Review

\title{
Diversity Oriented Syntheses of Conventional Heterocycles by Smart Multi Component Reactions (MCRs) of the Last Decade
}

\section{Heiner Eckert}

Department Chemie, Technische Universität München, Lichtenbergstr. 4, Garching 85747, Germany; E-Mail: eckert@tum.de; Tel.: +49-89-354-5532; Fax: +49-89-289-13329

Received: 9 December 2011; in revised form: 11 January 2012 / Accepted: 12 January 2012 /

Published: 20 January 2012

\begin{abstract}
A collection of smart multicomponent reactions (MCRs) with continuative post condensation cyclizations (PCCs) is presented to construct conventional three- to sevenmembered heterocyclic compounds in diversity oriented syntheses (DOS). These will provide a high degree of applying economical and ecological advantages as well as of practicability. Water, ionic liquids, and solvent-less syntheses as well as use of various forms of energy as microwave and ultrasonic irradiation are examined and discussed.
\end{abstract}

Keywords: multicomponent reaction; MCR; MFCR; I-MCR; isocyanide; heterocycle; diversity oriented synthesis; solvent-less synthesis; alternative energy; microwave

\section{Introduction}

Multi Component Reaction (MCR) chemistry [1,2] applied to the synthesis of heterocycles [3-5] with all its variations and extensions has undergone an enormous and meaningful upturn. Seeds sown in the last century, particularly appreciated by Ugi [6], have grown enormously and provided a plurality of novel reactions, new smart strategies as well as forward-looking methods, and high product diversity [7,8]. In this paper syntheses of conventional three to seven-membered heterocyclic structures (aziridine, azetidine, pyrrole, pyrrolidine, furan, indole, isoindoline, pyrazole, pyrazoline, imidazole, oxazolidine, thiazole, triazole, triazolidine, tetrazole, pyridine, pyrane, isoquinoline, pyrimidine, piperazine, oxazine, tetrazine, and oxadiazepine) are presented. The heterocycles are listed in Section 2, in ascending order, firstly by ring-size 3 to 7, secondly by number of hetero atoms 1 to 4 , and thirdly by hetero atoms $\mathrm{N}, \mathrm{O}, \mathrm{S}$. 


\subsection{Times and Progress}

First of all, three syntheses of indole/indole derivatives, according to (1) [9], (2) [10], and (3) [11] in Scheme 1, shall demonstrate the course of time and progress in research, how reactions and their conditions became better in terms of ecology and economy, i.e., reaction temperatures fell from $360{ }^{\circ} \mathrm{C}$ to r.t. (room temperature) and $-78{ }^{\circ} \mathrm{C}$, reaction times decreased from $16 \mathrm{~h}$ to $30 \mathrm{~min}$ and product yields increased from $60 \%$ to $100 \%$ (Table 1 ).

Scheme 1. Indole syntheses (1)-(3) under various reaction conditions.
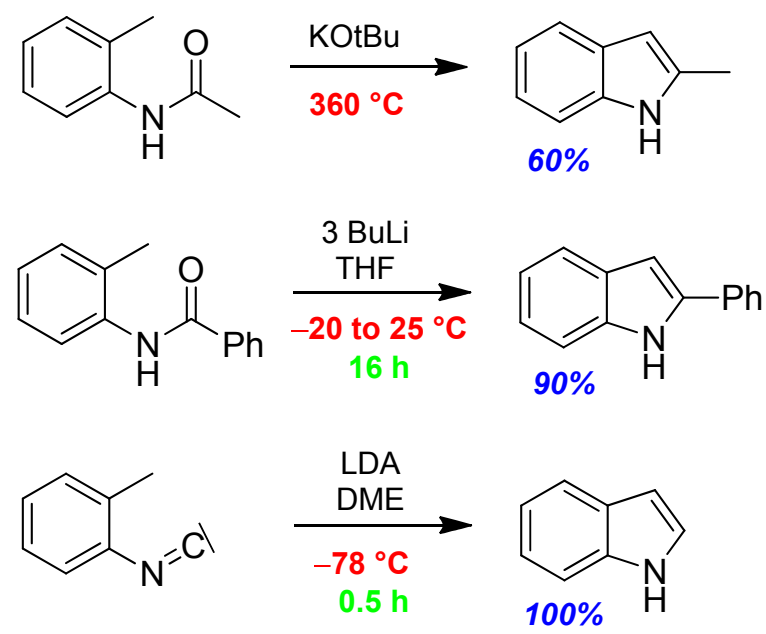

To compare data of not exactly identical products is problematic, but the principal trend in the different data is evident.

Table 1. Reaction data of indole syntheses (1)-(3).

\begin{tabular}{lccc}
\hline Reaction-conditions & Madelung Synth. (1) & Modified Madelung (2) & Saegusa Synth. (3) \\
\hline Publ. year & 1912 & 1981 & 1977 \\
Base & KOtBu & $\mathrm{BuLi}$ & LDA \\
Temp $\left[{ }^{\circ} \mathrm{C}\right]$ & 360 & -20 to +25 & -78 \\
Time $[\mathrm{h}]$ & n.a. & 16 & 0.5 \\
Yield [\%] & 60 & 90 & 100 \\
\hline
\end{tabular}

Beyond this, (3) shows, that using an isocyanide function the reaction becomes faster. This advantage of highly reactive isocyanide reagents is also evident for isocyanide-based MCRs (I-MCRs) such as the Passerini- and Ugi-reactions [6] as well as novel I-MCRs presented in sub-section 3.2.

\subsection{Nomenclature}

Due to the rapid progression of MCRs by processing additional functions and its extensions into domino- and post-condensation-cyclisations (PCCs) (sub-sections 3.4 and 3.5), the hitherto existing nomenclature is no longer sufficient for many cases and becomes sometimes unwieldy and imprecise. A consequence of these impacts is a different counting of components and active functions. The latter can be emcompassed within the phrase "Multi-Function-Component-Reaction" or "MFCR", respectively [2], and is so used in this article. i.e., when the number of functions in the reaction 
involved exceeds the number of components, the former will be prefixed to the latter. For example, U-5F4CR means an Ugi four component reaction with five participating functions, as is in following sub-section 2.1. Often the extension of functions will cause a domino-reaction.

\section{High Diversity in Heterocycle Syntheses with MCRs}

Nowadays nearly all heterocycles can be constructed using MCRs. Here, a survey of recent developments on Diversity Oriented Syntheses (DOS) will be reported [7,8]. Diversity of products is increasing by both versatile and smart MCRs and many consecutive further reactions like versatile domino-reactions and post-condensation-cyclisations (PCCs) [12,13]. This can also be achieved by an increase of the number of components, as in 5CR [14], 7CR [15], and 8CR [16], transition metal catalysed MCRs [17], and evolutionary chemistry aided MCRs [18]. Several recent diversity oriented reviews [19-26] demonstrate the high innovation and creativity in this seminal field of chemistry.

\subsection{Aziridine 3, U-5F4CR, 2-Alkoxyketone + Carboxylic acid + Amine + Isocyanide [27]}

Compound $\mathbf{1}$ is the bi-functional carbonyl component in the Ugi-four component reaction (U-4CR) in addition to carboxylic acid, isocyanide, and primary amine. After forming the $\alpha$-adduct 2, the generated sec. amine substitutes the vicinal alkoxy-group (formerly the second function of 1). The latter reacts with the acyl function of the aza-anhydride moiety forming the carboxylic acid ester by-product. The Ugi-reaction goes on to form the target molecule, the tetra-substituted aziridine derivative 3 (Scheme 2). Yields are moderate to good (38-84\%) [27].

Scheme 2. Synthesis of aziridine 3 by U-5F4CR.
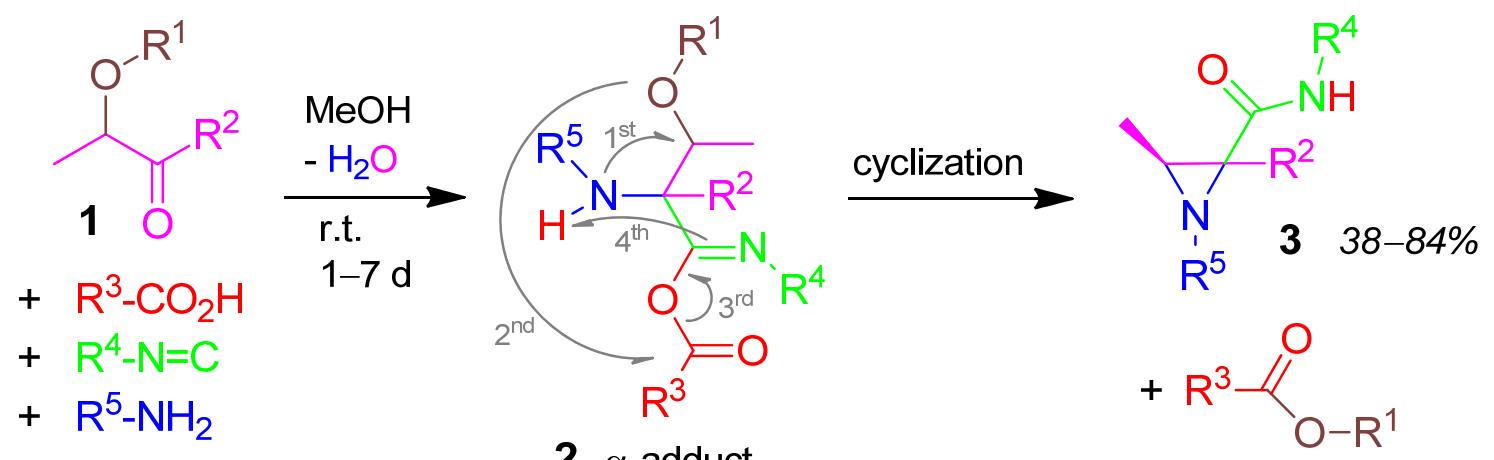

Further syntheses of aziridines and oxiranes are of 2-aminoketones from natural $\alpha$-amino acids [28], and S-ylide-mediated 3CR of alkylsulfonium salts with imines or aldehydes [29].

\subsection{Azetidinone 4, U-4F3CR, $\beta$-amino Acid + Aldehyde + Isocyanide [30]}

Tri-substituted azetidinone 4 is formed easily from $\beta$-amino acids by an Ugi-4F3CR in $32-42 \%$ yield (Scheme 3) [30]. Thereby two functions amino- and carboxylic acid-groups are located in one component $\beta$-amino acid. A review on $\beta$-lactam antibiotics syntheses by similar MCRs has been published [31]. 
Scheme 3. Synthesis of azetidinone 4 by U-4F3CR.

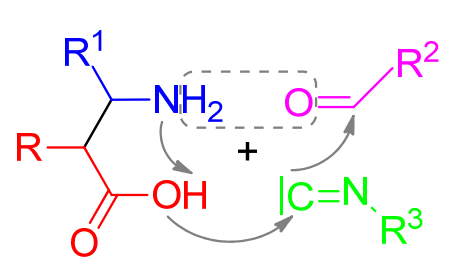

$\beta$-amino acid

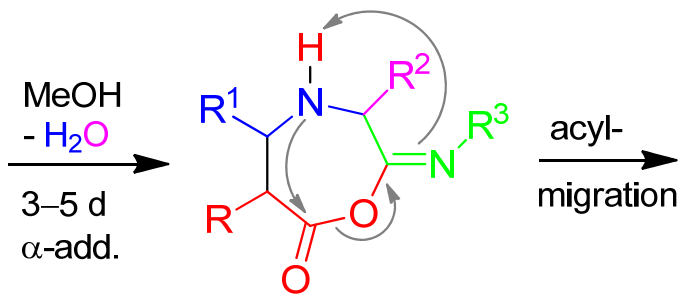

$\alpha$-adduct<smiles>[R]NC(=O)C([R])N1C(=O)C([R])C1[R]</smiles>

$4 \quad 32-42 \%$

\subsection{Azetidine 6, 3CR, Azabicyclo[1.1.0]butane + 2,3-Dicyanofumarat + Alcohol [32]}

The azabicyclo[1.1.0]butane building block 5, recently used on various occasions, reacts in a 3CR with Michael-acceptor 2,3-dicyanofumarate and alcohols to form pentasubstituted azetidines 6 in moderate to excellent yields of 52-96\% (Scheme 4) [32].

Scheme 4. Synthesis of azetidine 6 by $3 C R$.

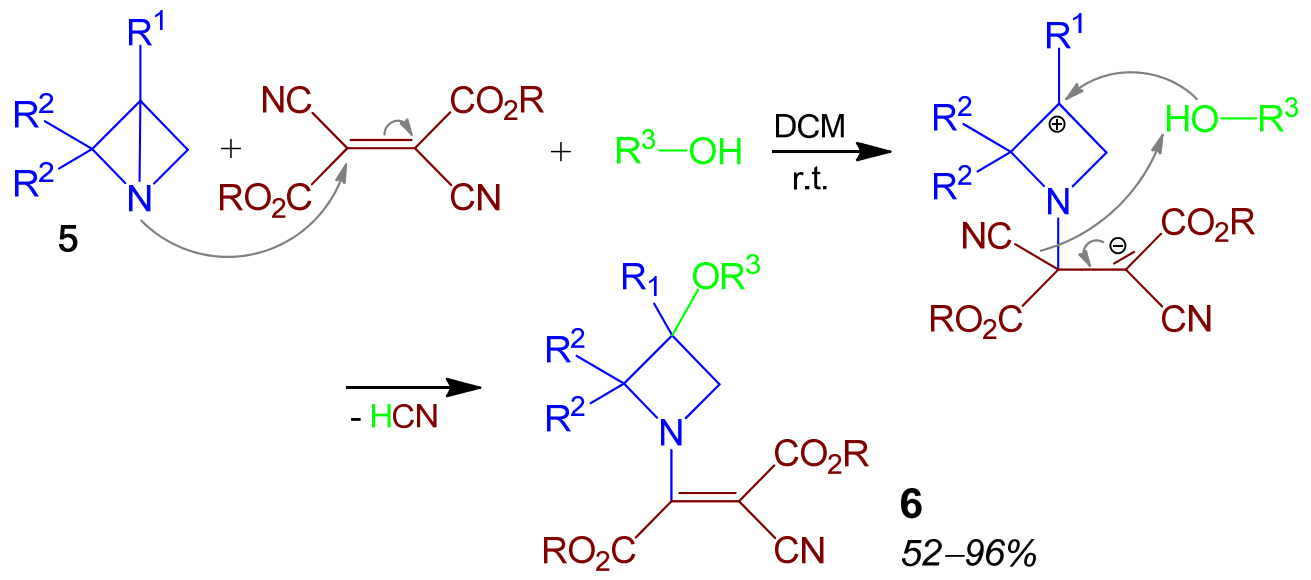

\subsection{Pyrrole 7, H-4F3CR, 2-Ketoester + Amine + Fumaric Dichloride [33]}

This Hantzsch-4F3CR forms pentasubstituted pyrrole derivatives 7 and runs solvent-less at r.t. to provide good yields (70-85\%) of 7 [33]. Thereby fumaric dichloride functions as Michael acceptor for the addition of the acetoacetate. Eliminating water transforms one acyl chloride into a carboxylic acid function (Scheme 5).

Scheme 5. Synthesis of pyrrole 7 by H-4F3CR.

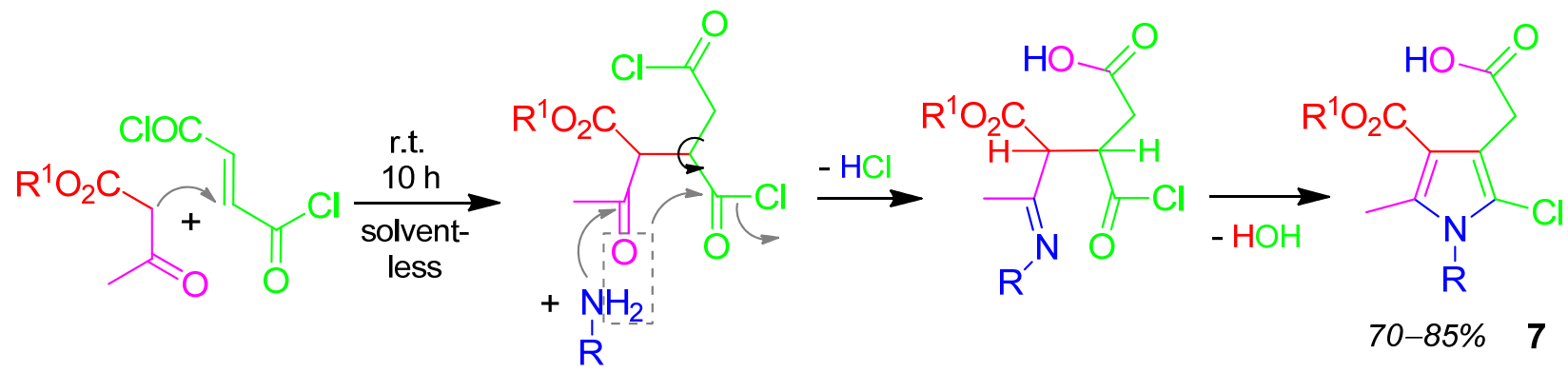


Another solvent-less synthesis of pyrrole from diazadiene + acetoacetate + amine has been performed with good yields of 56-84\% [34].

\subsection{Pyrrole 9, H-3CR, Acetylenedicarboxylate + Diacetyl + Ammonium Acetate [35]}

The deactivated alkyne dialkyl acetylenedicarboxylate is activated by $\mathrm{Ph}_{3} \mathrm{P}$ and reacts with the ammonium cation at r.t. to form the aminophosphorane 8. This undergoes a Wittig reaction with diacetyl and reacts further according to Hantzsch-3CR, affording the 2,3-dimethyl.4,5-dialkoxycarbonyl substituted pyrrole derivative 9 (Scheme 6) [35].

Scheme 6. Synthesis of pyrrole 9 by H-3CR.
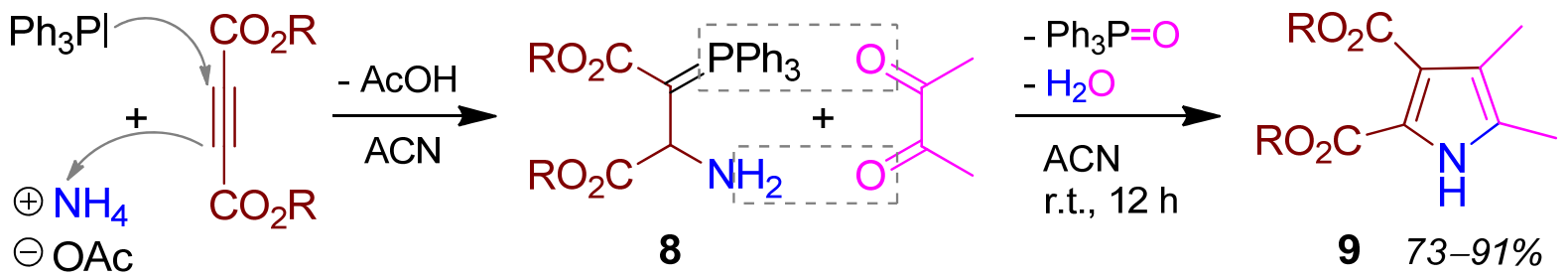

\subsection{Pyrrolidine 11, I-4CR, Aldehyde + Malodinitrile + Isocyanide + Phenanthridine [36]}

First part of the I-4CR is a Knoevenagel condensation of an aromatic aldehyde with malodinitrile. This intermediate reacts with an isocyanide to form a reactive ylide 10, which adds to the azomethine function of phenanthridine, furnishing the phenanthridopyrrolidine $\mathbf{1 1}$ in very good to excellent yields of $90-98 \%$ (Scheme 7) [36]. Elimination of HCN does not occur.

Scheme 7. Synthesis of pyrrolidine 11 by I-4CR.

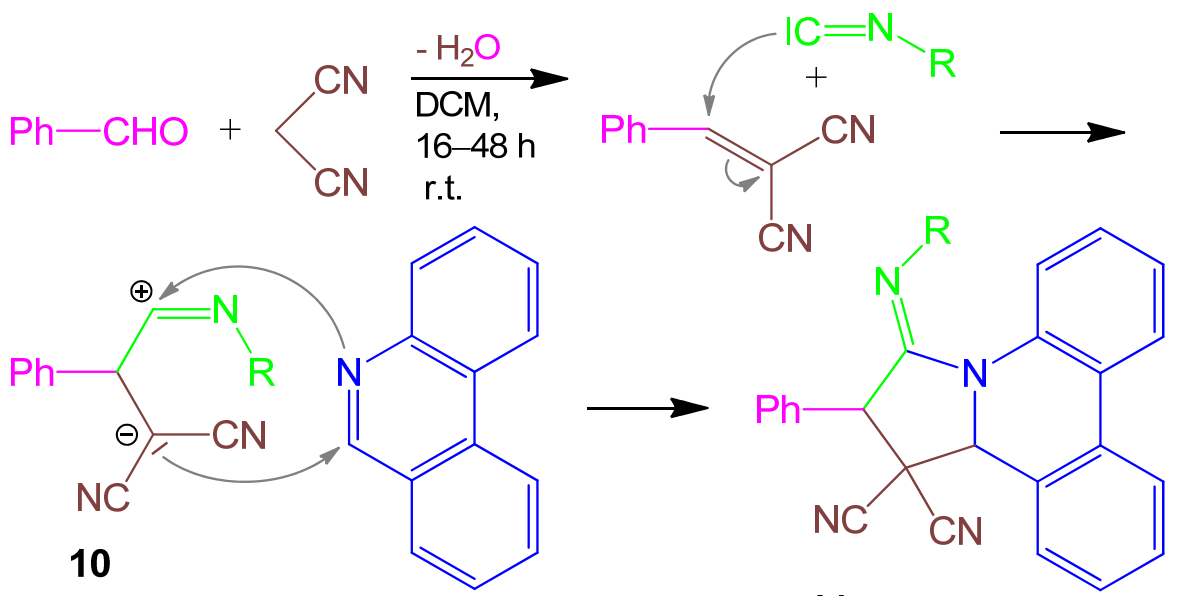

$1190-98 \%$

Further syntheses are a highly diastereoselective 3CR from aldehyde + aminomalonate + nitro-alkene to form 2,3,4,5-tetrasubstituted pyrrolidines [37], a chiral ruthenium porphyrin-catalyzed 3CR with chiral azomethine ylides [38], 4CRs of aldimines + acyl chlorides + alkynes + CO [39], and a reaction of alkyne $+p$-tolylsulfonylmethyl isocyanide (TosMIC) [40]. Two 3CRs with aniline + glyoxylate + bromobenzophenone [41] and diazoketone + nitroalkene + amine [42] have been 
performed. An extensive and critical review on the use of MCRs to synthesize pyrrole compounds has been published [43].

\subsection{Amino-furan 13, I-3CR, Acetylenedicarboxylate + Acid + Isocyanide [44]}

In an I-3CR the deactivated alkyne dialkyl acetylenedicarboxylate is activated by $(\mathrm{Ph})_{3} \mathrm{P}$, which also deoxygenates the carboxylic acid acyl group, generating the 1,4-dipole 12, which reacts with the isocyanide in a [4+1] cycloaddition reaction. Final aromatisation by thermodynamically driven tautomerisation affords the tetrasubstituted aminofuran derivative 13 in good yields of 74-91\% [44] (Scheme 8).

Scheme 8. Synthesis of amino-furan 13 by I-3CR.
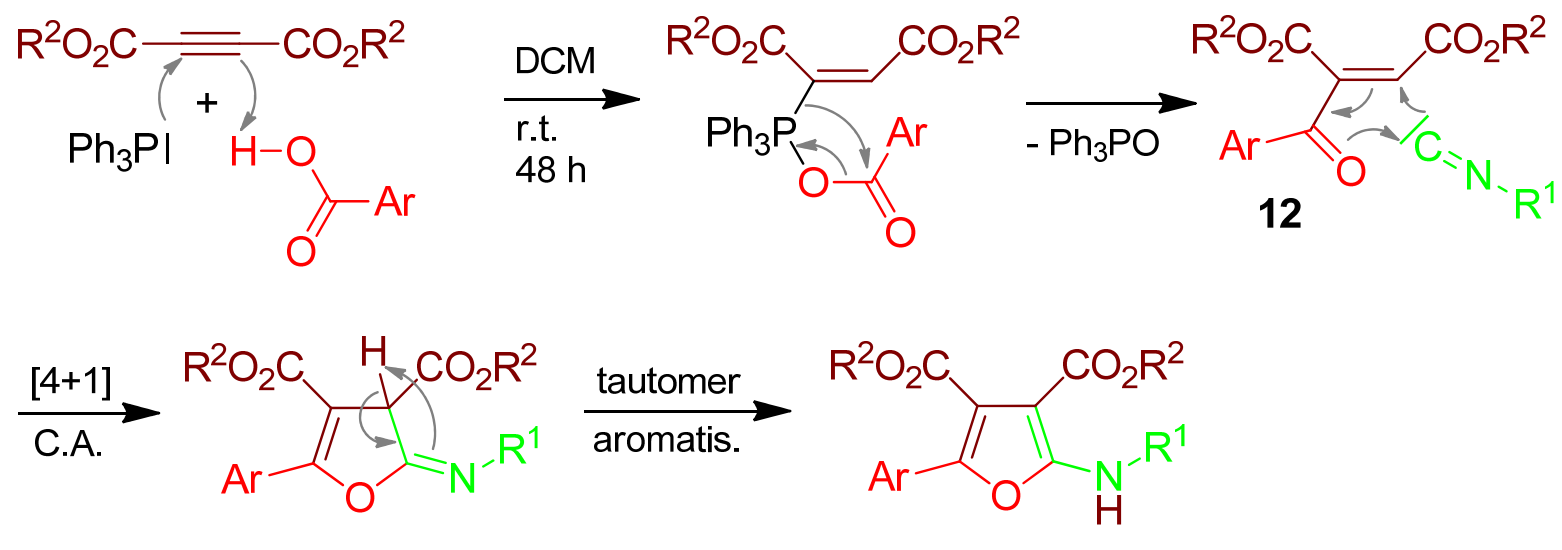

$74-91 \% \quad 13$

Further furan syntheses are a 3CR of salicylaldehyde + amine + alkyne, [45] and a 3CR performed with an imidazolium salt + alkyne + aldehyde [46].

\subsection{Indole 15, 3CR, Haloarylketone + Sulfoniumylide + Amine [47]}

The reaction of the ketone with the sulfonium ylide forms the epoxide intermediate $\mathbf{1 4}$ by elimination of dimethylsulfide. Compound $\mathbf{1 4}$ reacts with a primary amine in a microwave assisted Corey-Chaykovsky reaction affording the indole derivative 15 in $40-92 \%$ yield (Scheme 9) [47]. Last step is the thermodynamically driven aromatisation by $\beta$-elimination of water.

Scheme 9. Synthesis of indole 15 by Corey-Chaykovsky 3CR.

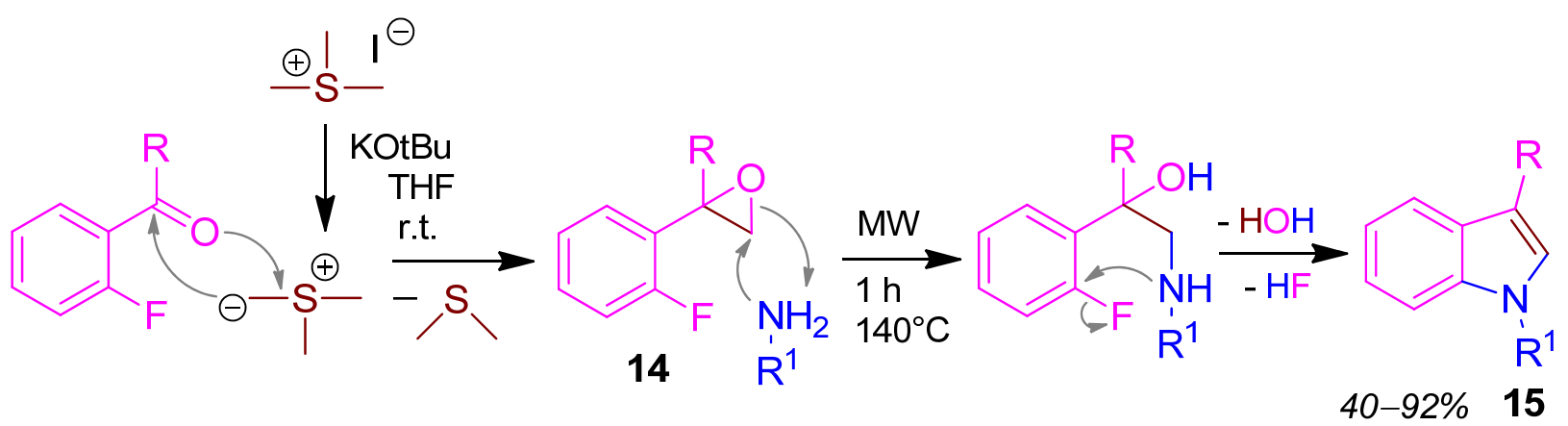


Further indole syntheses by multi-component reactions are a new 3CR Fischer indole syntheses based on new reactions of organometallic reagents with nitriles and carboxylic acids, which extend scope and synthetic utility of these syntheses [48], MCR of indoles from 2-iodobenzoic acid [49], and highly diversified indole scaffolds by U-4CR [50].

\subsection{Pyrazole 17, I-3CR, Acetylenedicarboxylate + Isocyanide + Semicarbazide [51]}

The isocyanide reacts in an I-3CR with the deactivated alkyne dialkyl acetylenedicarboxylate to form a reactive dipole intermediate 16, which reacts with the hydrazine moiety of semicarbazide. In the last step formamide is eliminated as a by-product, providing the aromatic 3,4,5-trisubstituted pyrazole derivative 17 (Scheme 10) [51].

Scheme 10. Synthesis of pyrazol 17 by I-3CR.
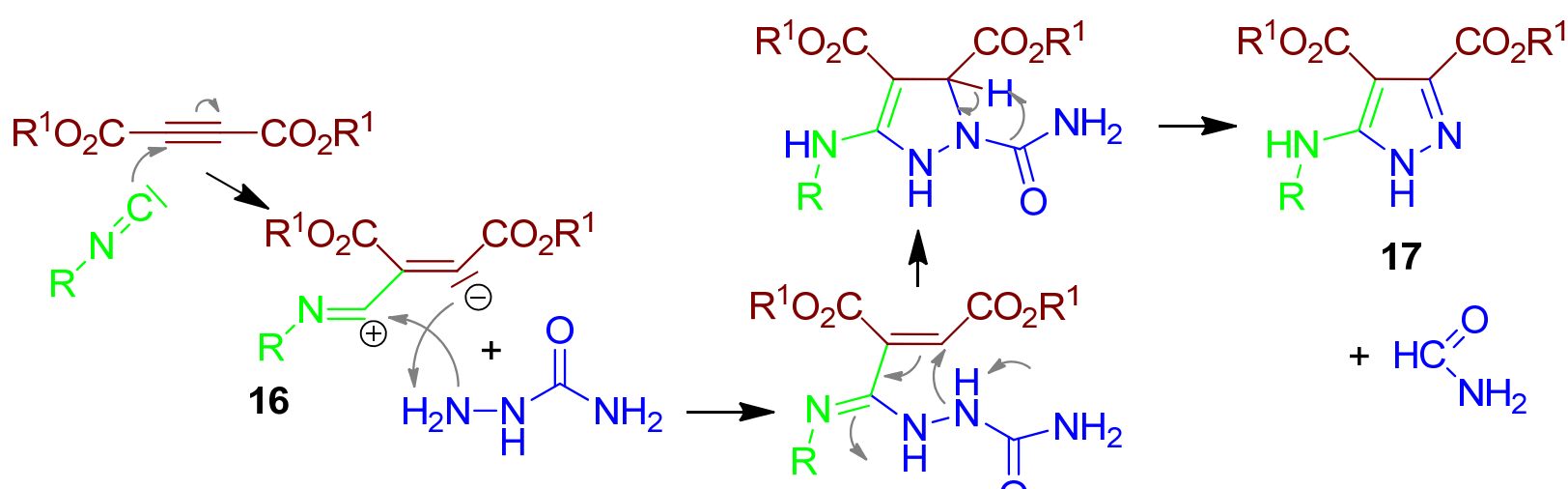

A new and environmentally-friendly method for preparing dihydropyrano[2,3-c]pyrazoles in water as solvent and under ultrasound irradiation has been developed [52].

\subsection{Pyrazoline 19, 3CR / PCC, Cyclopropylketone + Amine + Aldehyde / + Hydrazine [53]}

Cyclopropylphenylketone and $p$-chlorobenzaldehyde react to form the aldol addition product. This undergoes with diethylamine $\beta$-elimination of $\mathrm{H}_{2} \mathrm{O}$ affording the 3-CR product Michael acceptor 18 . Methylhydrazine reacts regioselectively with $\mathbf{1 8}$ according to the HSAB-concept in a PCC forming the pyrazoline derivative 19 with $72 \%$ yield and an anti/syn ratio of 3 (Scheme 11) [53].

Scheme 11. Synthesis of pyrazoline 19 by $3 \mathrm{CR} / \mathrm{PCC}$.
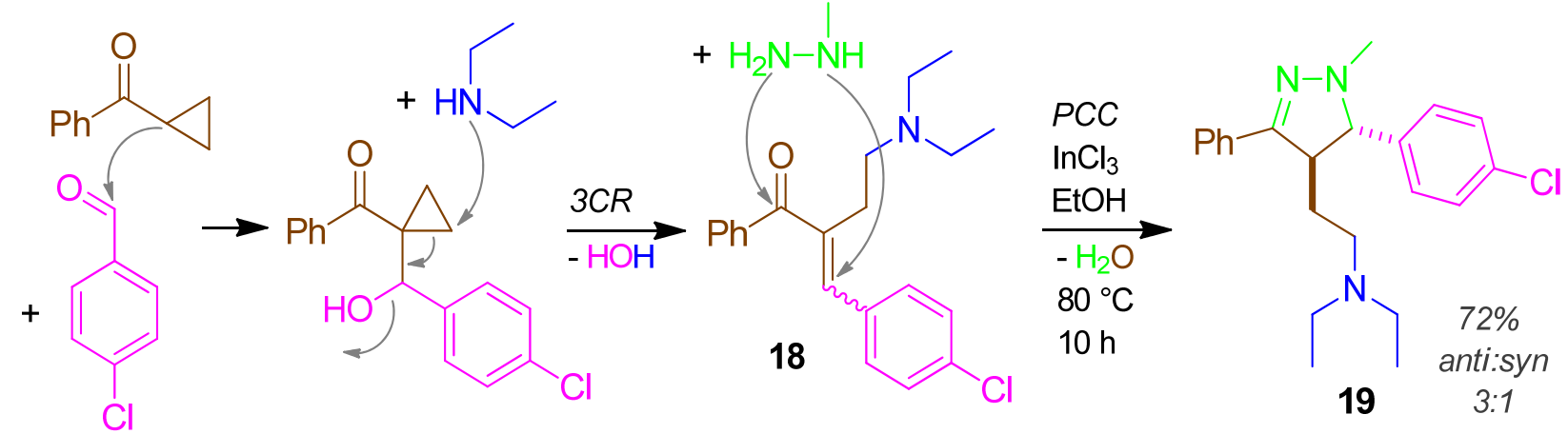
2.11. Imidazole 21, U-5F4CR / PCC, Acid + Amine + 2-Ketoaldehyde + Isocyanide / $+\mathrm{NH}_{3}[54]$

The U-4CR of benzoic acid, $n$-butylamine, 2-ketophenylacetaldehyde, and cyclohexylisocyanide provides 20, which reacts with ammonia (from ammonium carbonate) in a PCC cyclic amidination reaction to form the 1,2,3,5-tetrasubstituted imidazole 21, yield is 73\% (Scheme 12) [54].

Scheme 12. Synthesis of imidazole 21 by U-5F4CR/PCC.

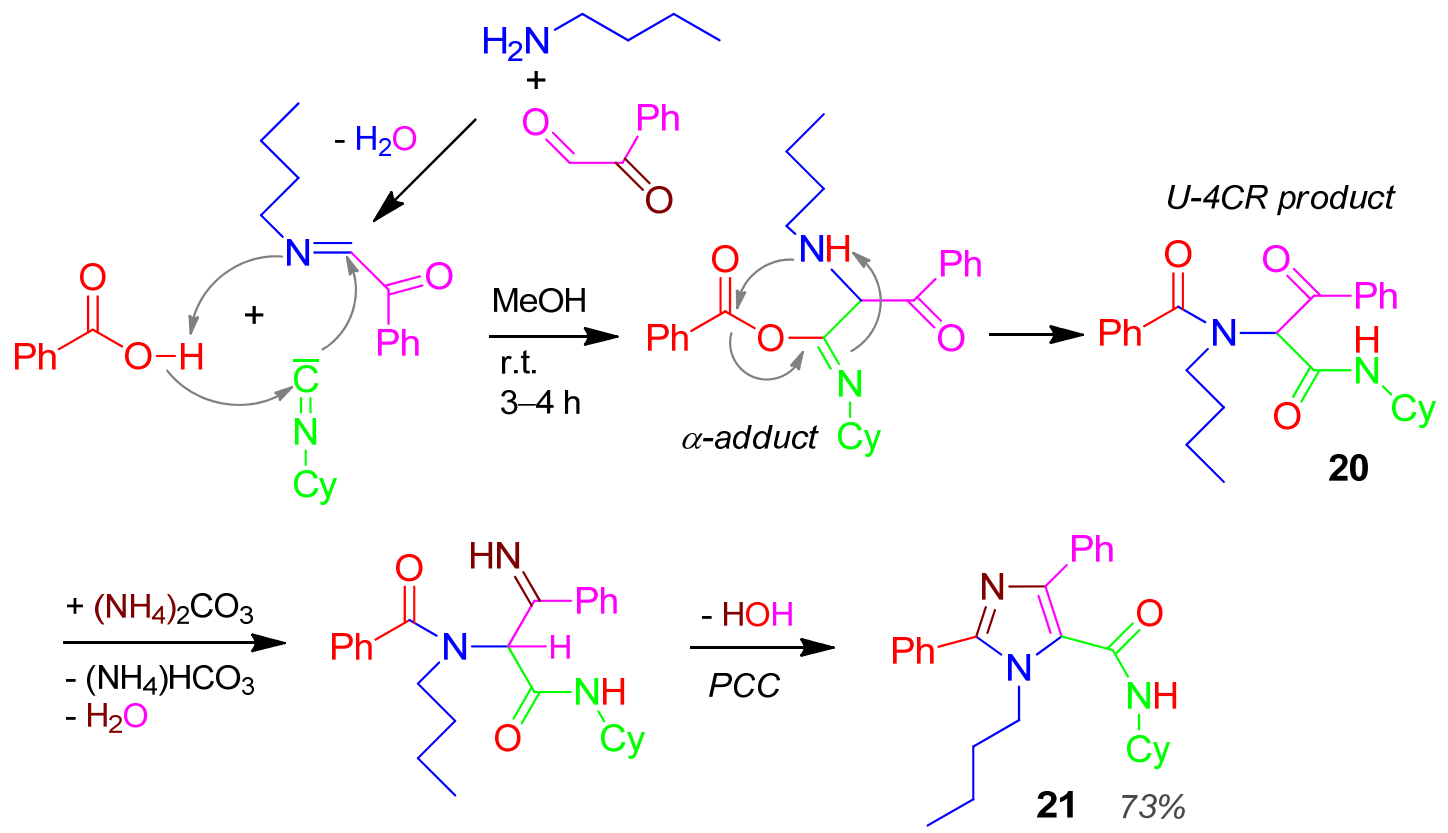

Further syntheses of imidazoles are MCRs from 1,2-diketone + aryl aldehyde + amine $+\mathrm{NH}_{3}$ [55] and from aziridine + alkyne $+\mathrm{TsN}_{3}$ [56]. TosMIC-based 3CRs form 4,5-disubstituted imidazole derivatives in good yields of $62-86 \%$ [57]. 4CRs from benzil + benzaldehyde + aniline + ammonium acetate in the ionic liquid butylmethyl imidazolium bromide as solvent [58] or solvent-free with "solid carbon acid" as catalyst [59] and both conventional or microwave-assisted, provide tetraaryl-substituted imidazoles both in very good yields.

\subsection{Imidazolium Salt 25, I-3CR, N-methyldihydropyridin $+2 x$ Isocyanide + Iodine [60]}

A direct access to benzimidazolium salts has been achieved by a 3CR with $N$-methyldihydropyridine-3-carboxylate, two cyclohexyl isocyanides and iodine. The proposed reaction mechanism is rather complex. Core steps of the reaction are the double $\alpha$-addition of isocyanides forming 22, the rearrangement of the dihydropyridine into the aza-bicyclo[2.2.2] octadiene structure 23. Ring-opening of $\mathbf{2 3}$ and ring-closure furnish the benzimidazolic zwittwerionic structure 24. Full aromatisation of $\mathbf{2 4}$ is thermodynamically driven and affords finally the benzimidazolium iodide $\mathbf{2 5}$ in a high yield of $85 \%$ (Scheme 13) [60].

A similar approach to create a mesoionic structure has been performed by a $3 \mathrm{CR}$ from isocyanide + isochinoline + trifuoroacetic anhydride (TFAA) forming an isochinolinoimidazoliumylide [61] 
Scheme 13. Synthesis of imidazolium salt 25 by I-3CR.

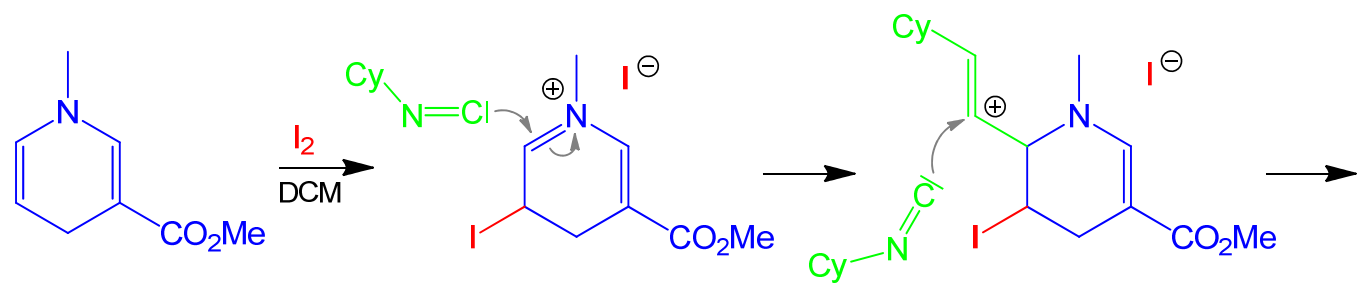

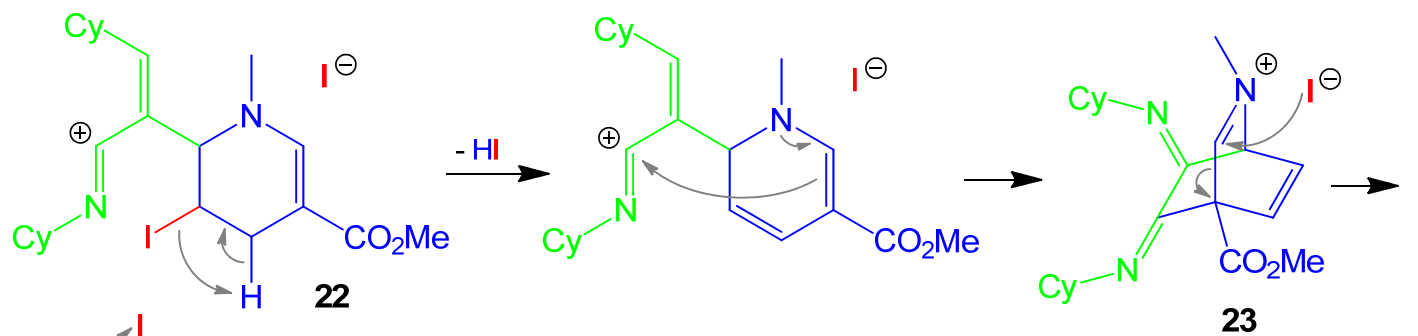<smiles>CC(=O)c1ccc2c(c1NC1CCCCC1)n(C1CCCCC1)c[n+]2C</smiles>

2.13. Oxazolidinone 27, 3CR, Aldehyde + Amine + Alkyne $+\mathrm{CO}_{2}[62]$

After condensation of aldehyde and amine to the imine, this reacts with the alkyne (CuI-catalyzed) to form 26. This cyclizes with carbon dioxide to afford the 3,4,5-trisubstituted 1,3-oxazolidin-2-one 27 quantitatively [62]; the overall yield is $63 \%$ (Scheme 14).

Scheme 14. Synthesis of oxazolidinone 27 by 3 CR.

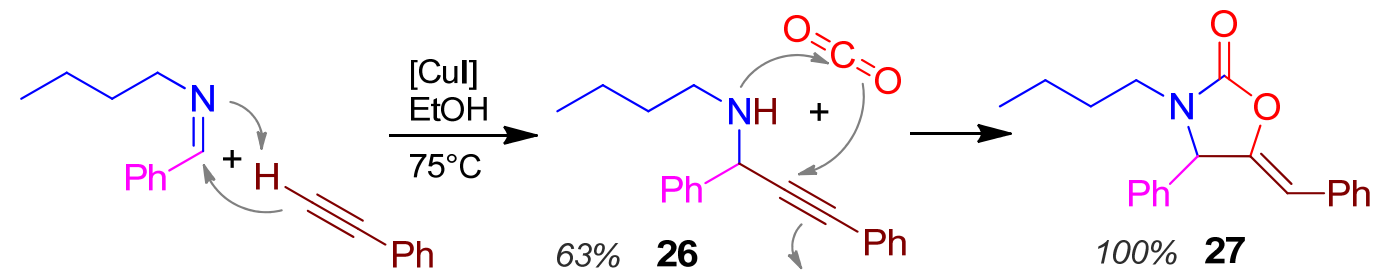

A 3CR from isocyanoacetate + aldehyde + amine provides trisubstituted oxazoles in good yields of up to $96 \%[63]$.

2.14. Thiazole 30, Domino U-4CR / PCC, Thioacid + Amine + Isocyanide + Aldehyde [64]

A U-4CR reaction effects the transfer of the thiol group onto the isocyanide carbon atom. After tautomerization of the thio group in the Ugi product 29 into a thiol function, this adds to the Michael acceptor of the former Schöllkopf isocyanide $\mathbf{2 8}$ to form the 2,4-disubstituted thiazole derivative $\mathbf{3 0}$ in $74 \%$ yield via elimination of dimethylamine (Scheme 15) [64].

A further 2,4,5-trisubstituted thiazole domino $\mathrm{U}-4 \mathrm{CR} / \mathrm{PCC}$ is prepared from oxo-components + primary amines + thiocarboxylic acids + methyl 3-bromo-2-isocyanoacrylates [65]. 
Scheme 15. Synthesis of thiazole 30 by U-4CR/PCC.

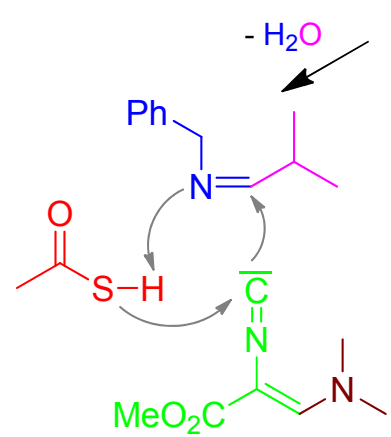

28

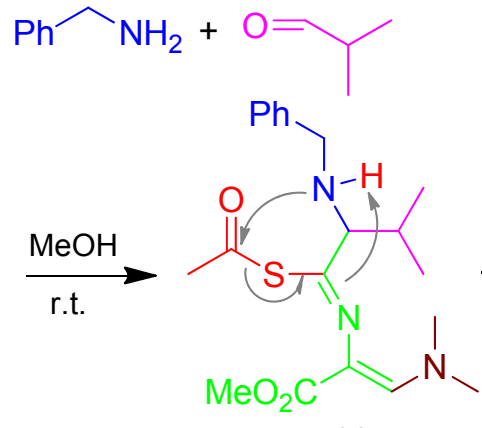

$\alpha$-adduct

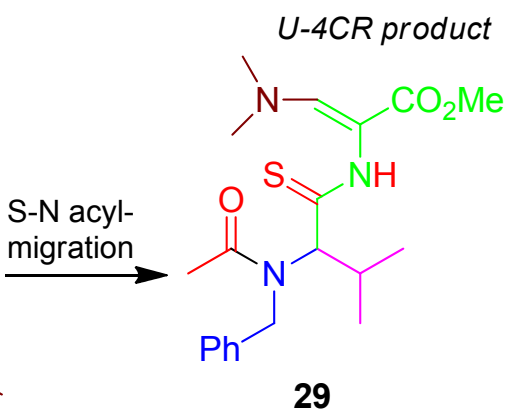

29

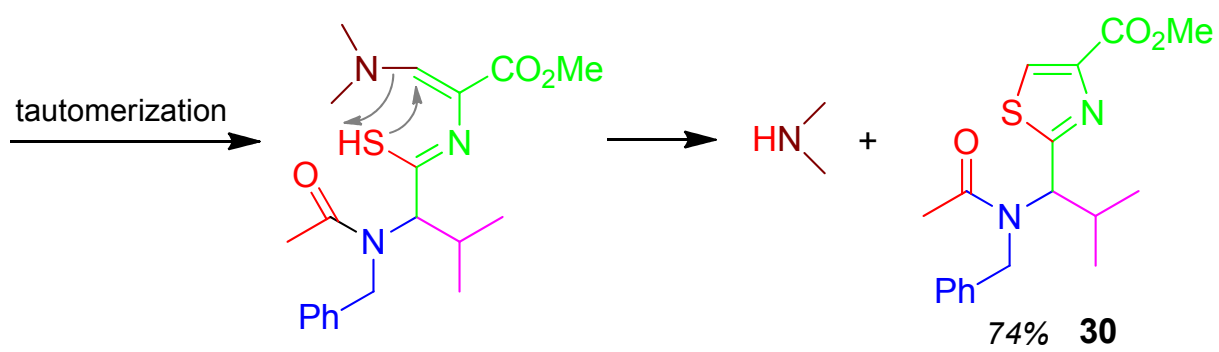

2.15. Oxazino-1,2,3-triazole 33, Domino P-5F3CR / PCC [3 + 2], Propiolic Acid + Isocyanide + Azido-aldehyde [66]

In a MW-assisted Passerini-3CR propiolic acid and azidoaldehyde added to an isocyanide ( $\alpha$-addition) affording the $\alpha$-adduct 31. The acyl group of the iminoester moiety migrates to the alcohol function of the former aldehyde moiety (acyl migration) to furnish the P-3CR product 32. The two additional acetylene and azide functions now react in a [3+2] cycloaddition forming the 1,2,3-triazole moiety of the final product $\mathbf{3 3}$ (Scheme 16). Azidoaldehydes are rather instable compounds, so they are employed in the synthesis as their corresponding azidoalcohols, which are oxidized by IBX directly before starting the P-3CR. Yields of 33 based on the azidoalcohols are $62-70 \%$ [66].

Scheme 16. Synthesis of oxazino-1,2,3-triazole 33 by P-5F3CR/PCC.
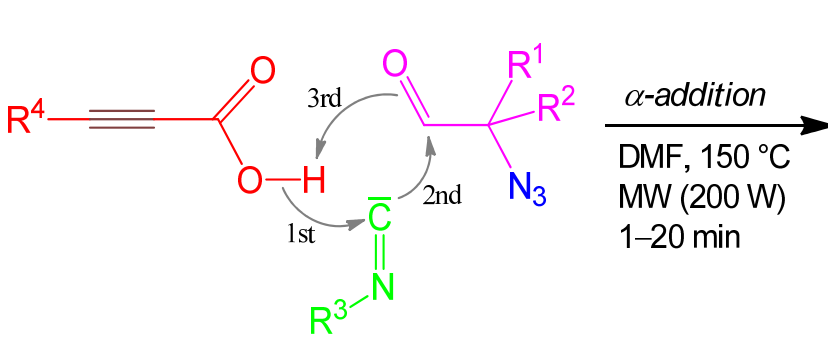

$1-20 \mathrm{~min}$

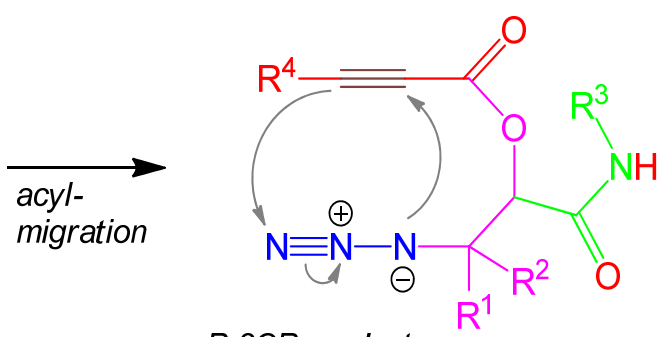

P-3CR product

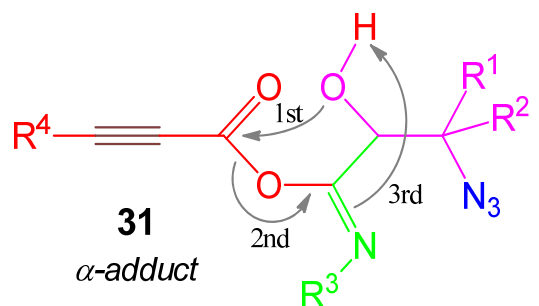

31<smiles>[R]NC(=O)C1OC(=O)c2c([R4])nnn2C1([R])[R]</smiles>

33 
Similar syntheses using U-4CRs instead of the P-3CR of before have also been performed [67]. Not a MCR, but a highly efficient $\mathrm{Cu}(\mathrm{I})$-isocyanide complex has been developed as a heterogeneous catalyst for azide-alkyne cycloaddition in water [68] to improve click chemistry (CC) [69-71].

\subsection{1,2,4-Triazolidine 35, 3CR, Azodidicarboxylate + Imine + Alkyl Diazoacetate [72]}

The 3CR of alkyl diazoacetate with an imine is catalyzed by ruthenium tetraphenylporphyrin (RuTPP) accompanied by the release of nitrogen and forming the strong 1,3-dipole azomethinylide 34, which reacts with the dialkyl azodicarboxylate to furnish in a stereocontrolled [3 +2$]$ cycloaddition reaction the pentasubstituted 1,2,4-triazolidine 35 in 70-82\% yield (Scheme 17) [72].

Scheme 17. Synthesis of 1,2,4-triazolidine 35 by $3 \mathrm{CR}$.

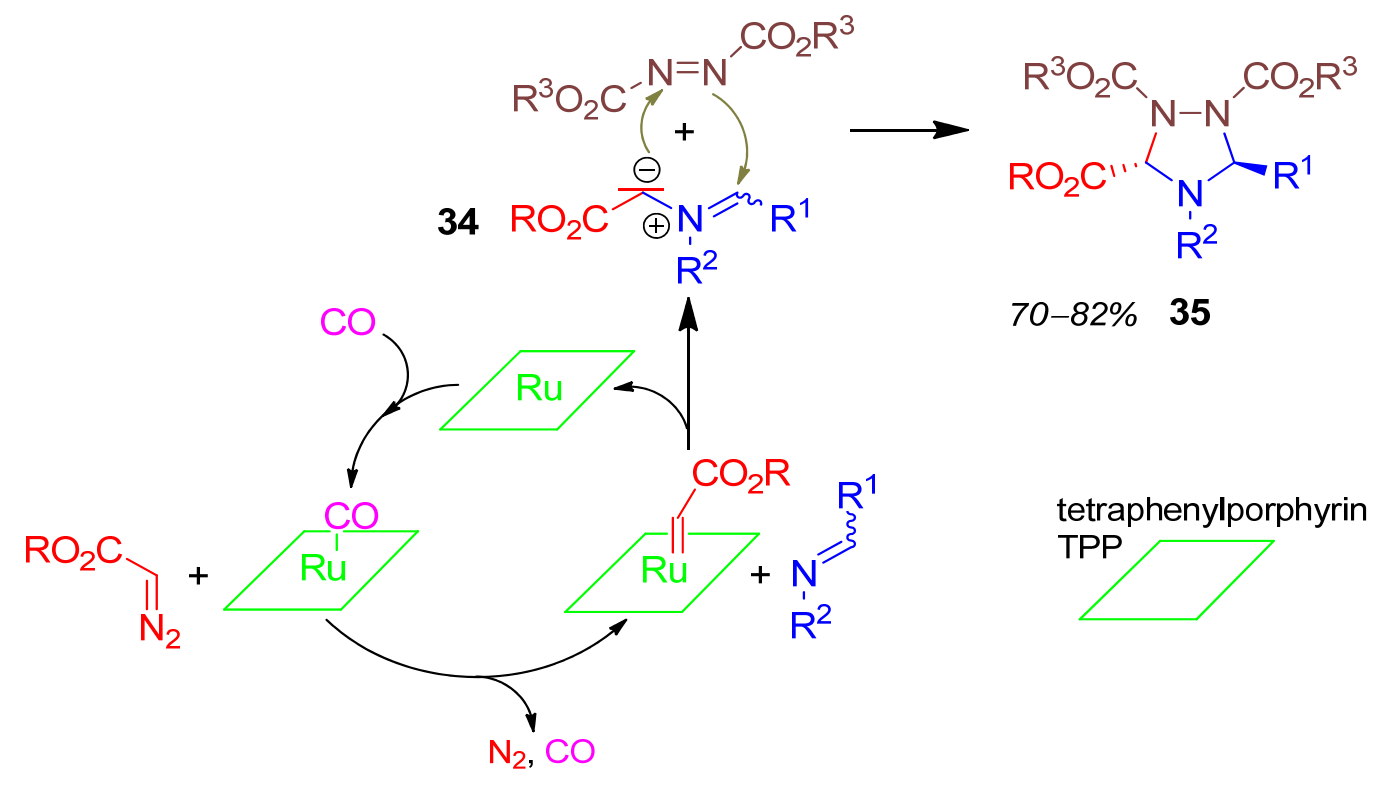

A general method for the synthesis of 1,3,5-trisubstituted 1,2,4-triazoles has been developed from 3CR of carboxylic acid + primary amidine + monosubstituted hydrazine [73]. This highly regioselective one-pot process provides high diversity and yields up to $78 \%$.

\subsection{Tetrazole 37, 3CR, Formic Acid Orthoester + Amine + Azide [74]}

Trimethyl orthoformate and amines react to form 36, which cyclise with $\mathrm{HN}_{3}$ to form the tetrazoles 37 in good yields of 70-92\%. The reaction runs without any solvent (Scheme 18) [74].

Scheme 18. Synthesis of tetrazole 37 by 3 CR.

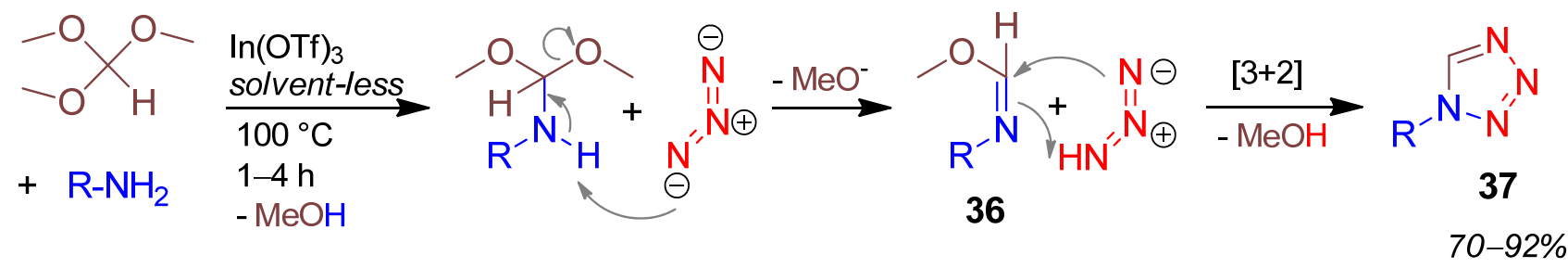


2.18. Tetrazolyl Isoindoline 40, Domino U-5F4CR / PCC, 2 x Cyclization Reaction, Methyl Formyl-benzoate $+\mathrm{HN}_{3}+$ Amine + Isocyanide [75]

In an U-4CR with $\mathrm{HN}_{3}$ as acidic component the $\alpha$-adduct $\mathbf{3 8}$ is formed and a 1,5-dipolar cyclization takes place affording the tetrazole 39. A PCC by an amide generation furnishes the isoindoline in the final product 40 with yields of 68-92\% (Scheme 19) [75]. I-3CR with isocyanide + bromine + azide provides 5-bromotetrazole quantitatively [76]. The bromo function can further react in a Suzuki-reaction giving a $97 \%$ yield of the subsequent product.

Scheme 19. Synthesis of tetrazolyl isoindoline $\mathbf{4 0}$ by U-5F4CR.

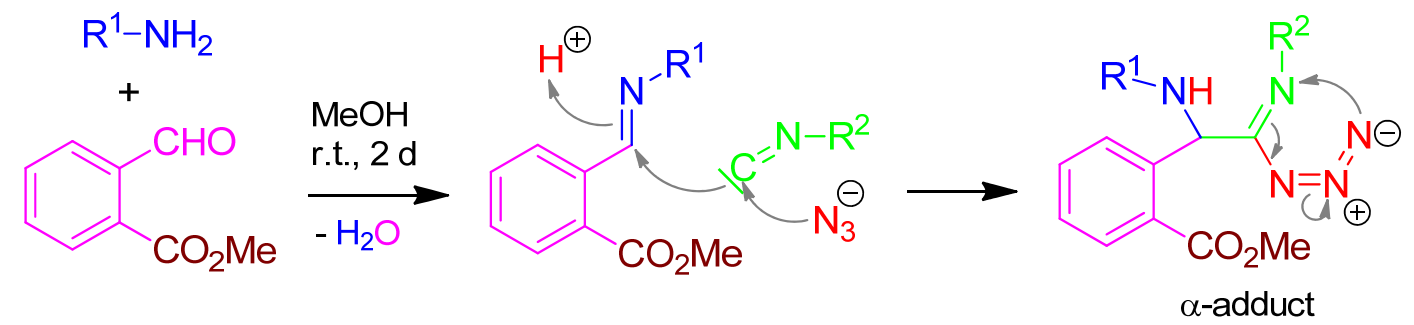

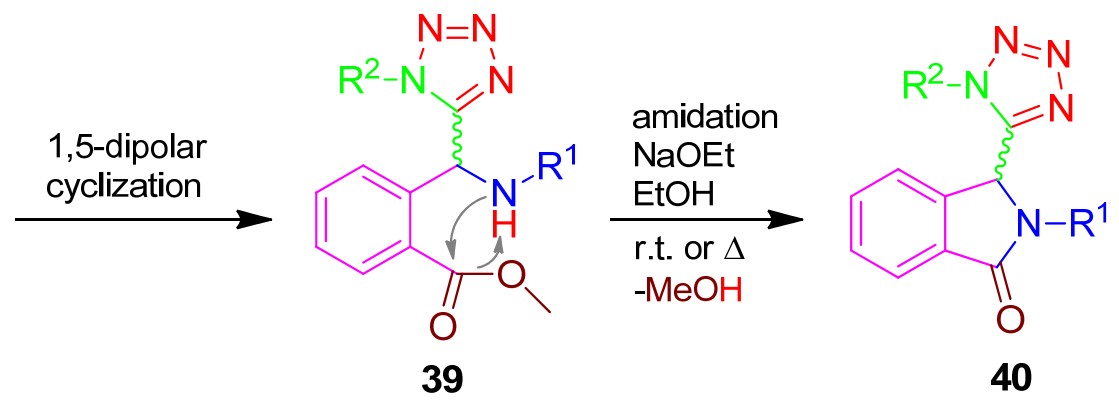

38

\subsection{Pyridine 45, Domino U-5F4CR / PCC, 2-Ketoacid + Amine + Aldehyde + Isocyanide [77]}

After reaction of 2-ketocarboxylic acid, amine, aldehyde, and isocyanide the resulting U-4CR-product 41 is deprotonated by hydroxide anion to form the strong carbanion $\mathbf{4 2}$, which isomerizes to give 43 . 1,6-Cyclization of $\mathbf{4 3}$ provides $\mathbf{4 4}$, which undergoes aromatization by dehydration to form the pyridine derivative 45 in good yields of 75 to $86 \%$ (Scheme 20) [77].

In a MW-assisted 3CR in water as solvent, isoxazolopyridines have been prepared in short reaction times of 6-9 $\mathrm{min}$ at temperatures of $100-130^{\circ} \mathrm{C}$ and in very good yields of $84-94 \%$ [78]. Solvent-less 4CR of acetylenedicarboxylate + malonitrile + amine + aldehyde provides pentasubstituted 2-aminopyridines in very good yields of 79-95\% [79]. A 3CR of pyrimidine + indole + aminoacryl-nitrile in water as solvent furnishes pyrazopyridine in a complex structure in high yields of 75-95\% [80]. Pyrazopyridines have also been synthesized in a 3CR in the IL butylmethyl imidazolium bromide or tetrafluoroborate as solvent in good yields of $79-95 \%[81,82]$.

Syntheses of pyrazolopyridines have been performed by $3 \mathrm{CR}$ from aldehyde + malodinitrile + aminopyrazole activated with both conventional heat (in refluxing ethanol) and ultrasound (45 kHz, $305 \mathrm{~W}, 60^{\circ} \mathrm{C}$ ) [83]. Yields have been $50-65 \%$ in conventional thermal and $85-98 \%$ in ultrasound driven reactions for the same ten products. 
Scheme 20. Synthesis of pyridine 45 by U-5F4CR.

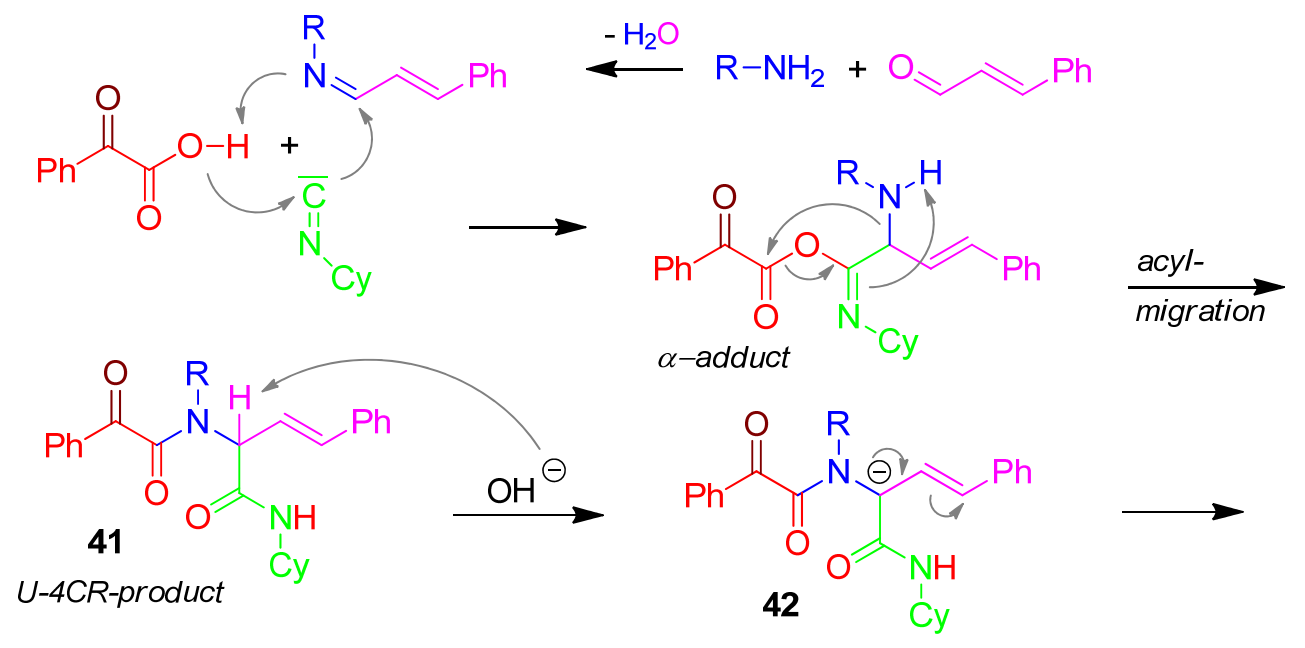

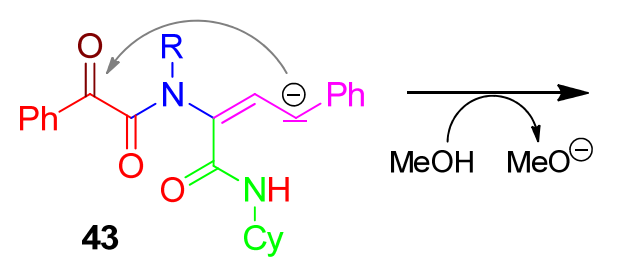<smiles>[R]N1C(=O)C(O)(c2ccccc2)C(O)(c2ccccc2)C=C1C(=O)NC1CCCCC1</smiles>

2.20. Pyran 47, Domino I-3F3CR/PCC, Acetylenedicarboxylate + Hydroxynaphthoquinone + Isocyanide [84]

Hydroxynaphthoquinone, acetylenedicarboxylate, and isocyanide react in an I-3CR to give 46, which cyclises to form the pyran derivative 47 in good yields of 60-89\% (Scheme 21) [84].

Scheme 21. Synthesis of pyrane 47 by I-3CR/PCC.

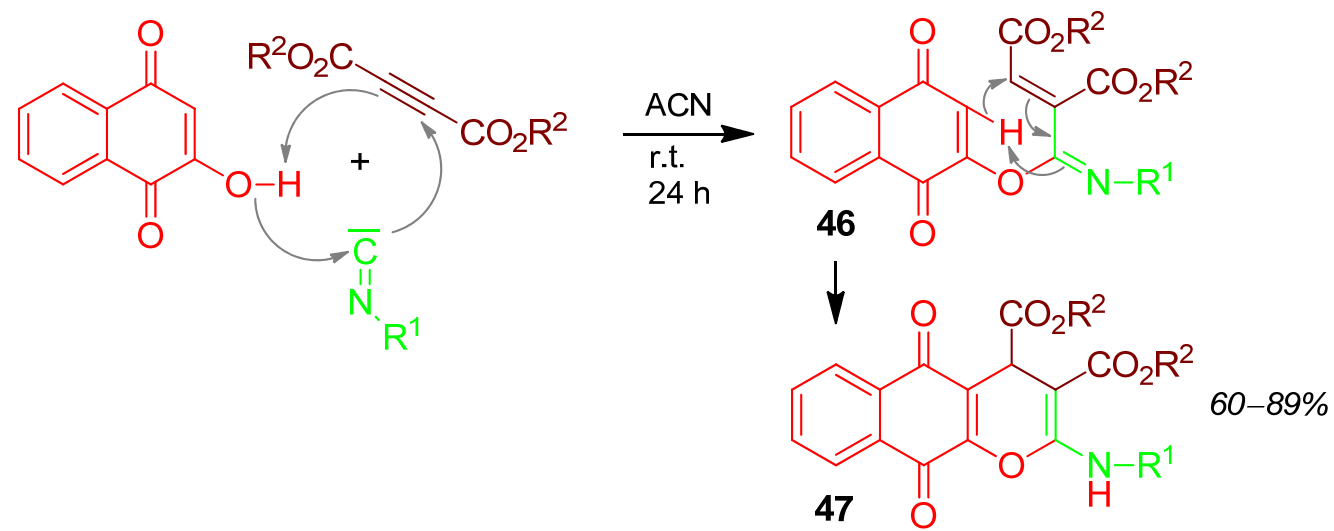

2.21. Isoquinoline 50, 5F4CR, Alkynylbenzaldehyde + Primary Amine + Formaldehyde + Secondary Amine [85]

The $\mathrm{Cu}(\mathrm{I})$ iodide-catalyzed 5F4CR of 2-ethynylbenzaldehyde, paraformaldehyde, diisopropylamine and tert.-butylamine affords $\mathbf{4 8}$, which further reacts to form a strong carbanion 49 . Its protonation provides the 2-aminomethylisochinoline $\mathbf{5 0}$ under elimination of isobutene as by-product [85] (Scheme 22). 
Scheme 22. Synthesis of isoquinoline $\mathbf{5 0}$ by $5 \mathrm{~F} 4 \mathrm{CR}$.

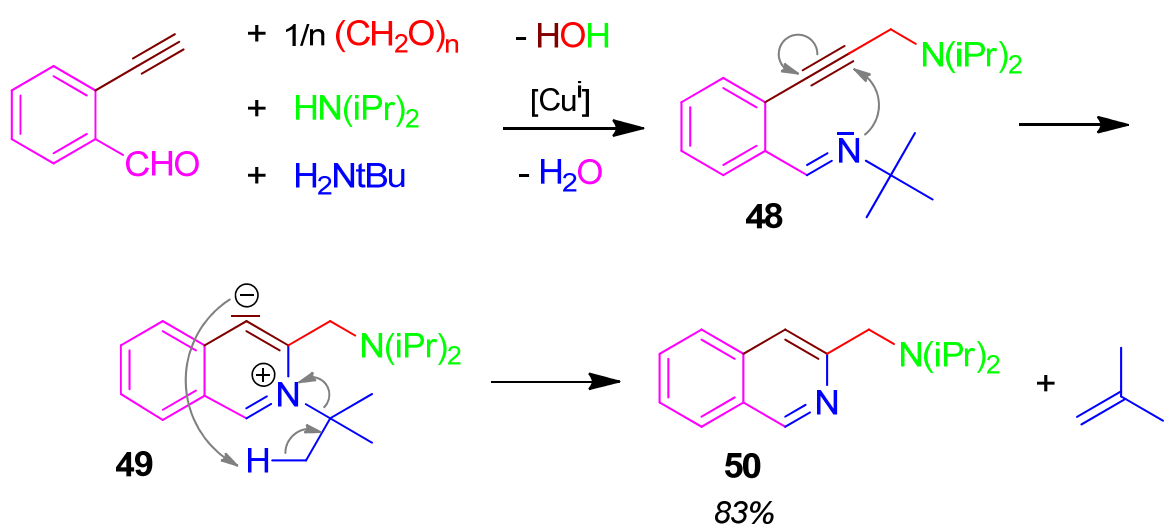

2.22. Pyridopyrimidine 52, I-4F3CR, 2-Aminopyridine + Acetylenedicarboxylate + Isocyanide [86]

Isocyanide-based 4F3CR from 2-aminopyridine, deactivated alkyne acetylenedicarboxylate, and isocyanide forms the zwitterionic compound 51, which reacts to yield the pyridopyrimidine 52 [86] (Scheme 23).

Scheme 23. Synthesis of pyridopyrimidine $\mathbf{5 2}$ by I-4F3CR.

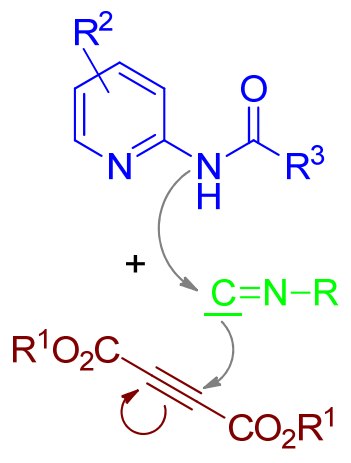

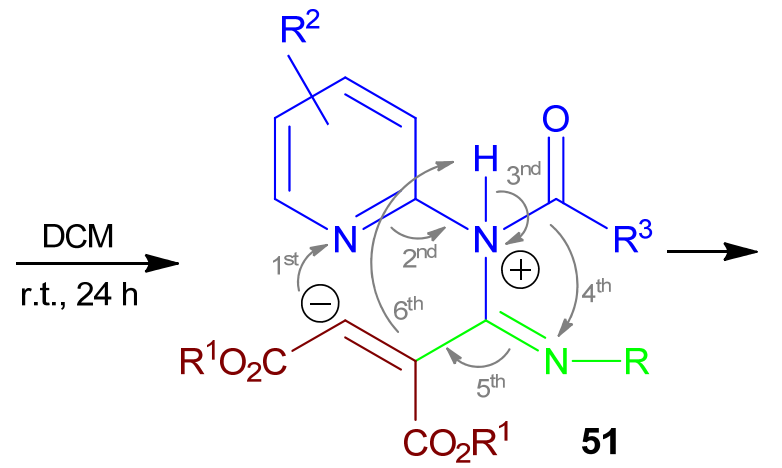<smiles>[R]CC(=O)C1=C(N([R])C([R])=O)N=C2C=CC=CN2C1C(=O)O[R2]</smiles>

52

2-Amino-5-cyano-pyrimidine-6-one has been synthesized by a 3CR of aldehyde + cyanoacetamide + guanidine [87]. An easy access for imidazopyrimidine derivatives from aldehyde $+1,3$-diketone + 2 -aminobenzimidazole with good yields of $60-82 \%$ is presented in [88].

\subsection{Piperazine 55, U-4F3C, Ketocarboxylic Acid + Amine + Isocyanide [89]}

In an Ugi reaction with both carboxylic acid and aldehyde functions connected in one component 53 with a neutral additional sulfonamide moiety, $\mathbf{5 3}$ reacts with an amine and an isocyanide to give the $\alpha$-adduct 54. After the acyl-migration at $\mathbf{5 4}$ the 1,4,6-tetrasubstituted piperazinone-derivative $\mathbf{5 5}$ is formed in 45-75\% yield (Scheme 24) [89]. A diversity-oriented synthesis (DOS) of a piperazine library with 90 analogs have been performed by use of MCRs [90]. A review on piperazine syntheses by MCRs has been published recently [91]. 
Scheme 24. Synthesis of piperazine 55 by U-4F3CR.
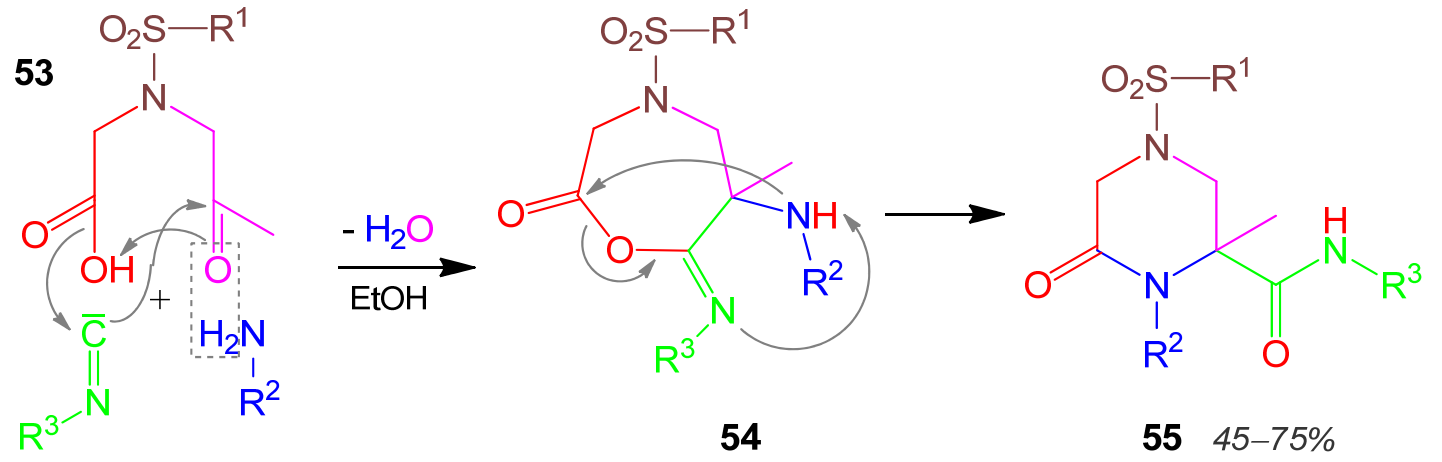

2.24. Tetrazinane 57, 3CR, Aldehyde + Urea + Ammonia [92]

In a 3CR benzaldehyde aminoacetal $\mathbf{5 6}$ is formed. A sequence of metathesis reactions connect the amino functions of both $\mathbf{5 6}$ and urea together forming 6-aryl-1,2,4,5-tetrazinane-3-one 57 in good yields of 68-80\% [92]. Two equivalents of hydrogen are released (Scheme 25).

Scheme 25. Synthesis of tetrazinane 57 by 3CR.

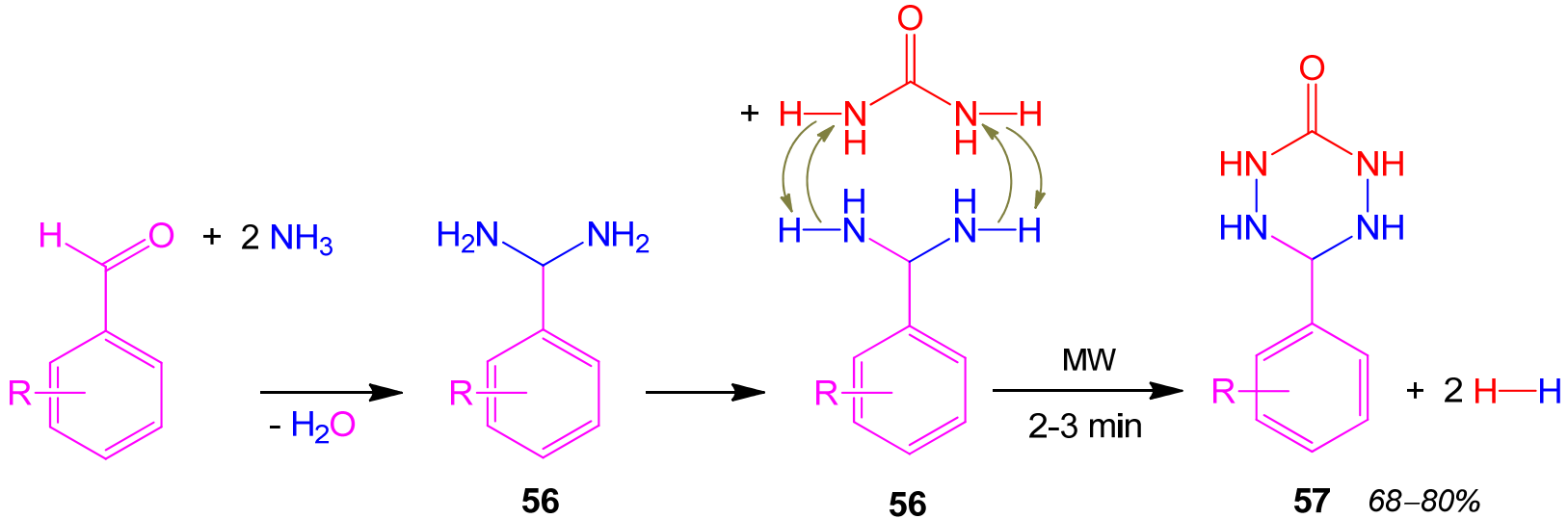

The proposed mechanism is favored by the lack of any solvent, so that N-H moieties are in direct contact with each other and are strongly activated by microwave irradiation (MW). A strong evidence for the proposed mechanism is given by comparing the data of the MW-supported reaction with the conventionally heated reaction. The MW-supported reaction rate is 15 fold and the product yield twice that of the conventionally heated process.

2.25. Oxadiazepine 59, U-6F4CR / PCC Staudinger-aza-Wittig reaction, Azidocarboxylic Acid + Aldehyde + Isocyanide + Aminoketone [93]

In an U-4CR wherein two components with two functions each, 2-aminobenzophenone, 2-azido-3phenylpropionic acid, benzaldehyde, and cyclohexyl isocyanide react forming the Ugi product $\mathbf{5 8}$ in $57-75 \%$ yield. A Staudinger-aza-Wittig sequence effects the ring closure furnishing the $(S)$-3-benzyl2-oxo-1,4-benzodiazepines 59, yields are 65-84\% (Scheme 26) [93]. The ketone carbonyl oxygen atom is removed by triphenylphosphane. 
Scheme 26. Synthesis of oxadiazepine 59 by U-6F4CR/PCC.
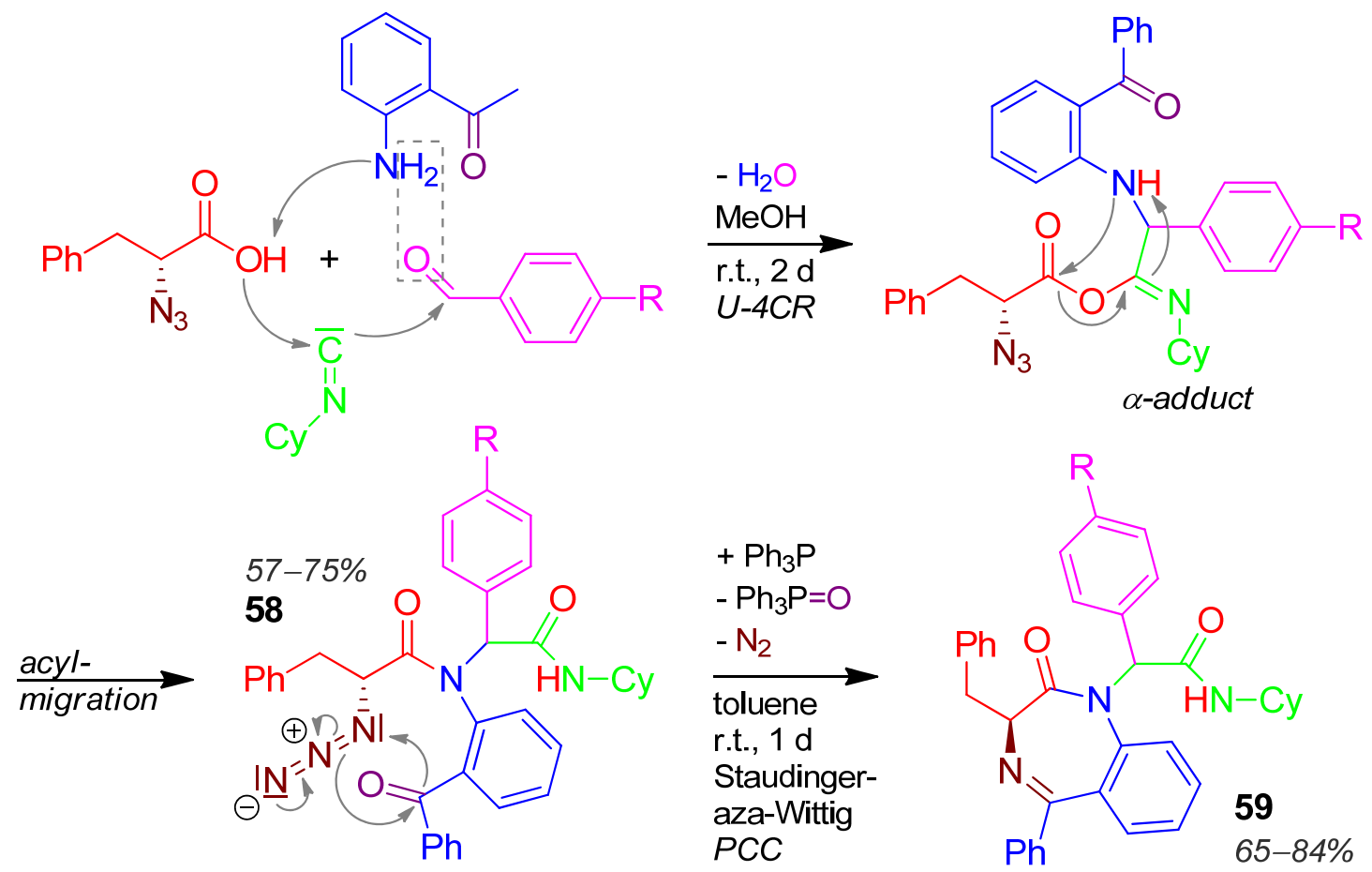

2.26. Oxadiazepine 62, Domino Aza-Wittig / I-3CR, Acetylenedicarboxylate + 1,3-Diketone + Isocyano-azaphosphorane [94]

The aza-Wittig-reaction of a 1,3-diketone with an isocyanoazaphosphorane provides the phosphaoxazetidine derivative 60, which enolises to give the isocyanide 61. This further reacts with dialkyl acetylenedicarboxylate to form the 1-oxa-3.4-diazepine derivative 62 (Scheme 27) [94].

Scheme 27. Synthesis of oxadiazepine 62 by I-3CR.

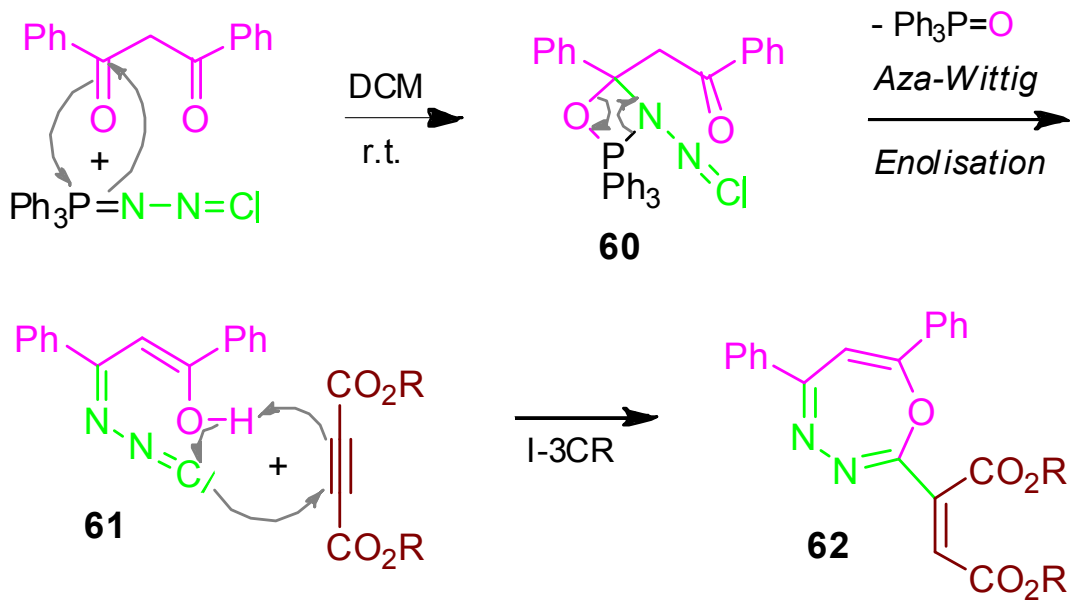

\section{Strategies in Designing Novel MCRs}

Several thermodynamic and reaction chemical effects as well as new strategies and new developed synthetic methods are smart and very advantageous ways to create novel MCRs. 


\subsection{Thermodynamic Effects}

The well-known strategy to effect an easy forming of heterocyclic compounds by aromatising them has been often applied in syntheses, as illustrated by almost half the reactions in this paper. There, a resonance energy in the range of $100 \mathrm{~kJ} / \mathrm{mol}$ is released. Particularly in the last step of a synthesis, the exergonic behavior makes this an irreversible one and affords good product yields. This is demonstrated by reactions with tautomerisations as the last step in sub-sections 2.7 and 2.20.

Another strategy to facilitate a reaction course is to accelerate the number of molecules on the product site of the syntheses. Thus, reaction entropy increases and facilitates cyclization. This can be done by introduction of appropriate substructures into the reaction paths, which will later become leaving groups to push the progress of the reactions, preferably in the last step. These are $\mathrm{H}_{2} \mathrm{O}$ in sub-sections 2.8, 2.11 and 2.19, $\mathrm{MeOH}$ in 2.17, $\mathrm{N}_{2}$ in 2.16., $\mathrm{CO}_{2}$ in 3.1.1, carboxylic acid ester in 2.1, dimethyl sulfide in 2.8, formamide in 2.9, dimethylamine in 2.14, isobutene in 2.21, isocyanate in 3.1.1, and even ketene in 3.1.2. The latter two by-products are somewhat unusual as leaving groups, so their reaction pathways will be discussed.

\subsubsection{Isocyanate 63 Elimination [95]}

The reaction is mediated by tert.-butyl isocyanide. By-product of the pyrrole derivative synthesis is tert.-butyl isocyanate $\mathbf{6 3}$, which comes from the oxygenation of tert.-butyl isocyanide with oxygen from the acyl moiety (Scheme 28), which leaves back the strong azomethineylide 1,3-dipole 64. This reacts with the acetylenedicarboxylate in a [3+2] cycloaddition affording the pentasubstituted pyrrole derivative $\mathbf{6 5}$ in good yield of $84 \%$ [95].

Scheme 28. Isocyanate $\mathbf{6 3}$ formation as by-product in a pyrrole synthesis.

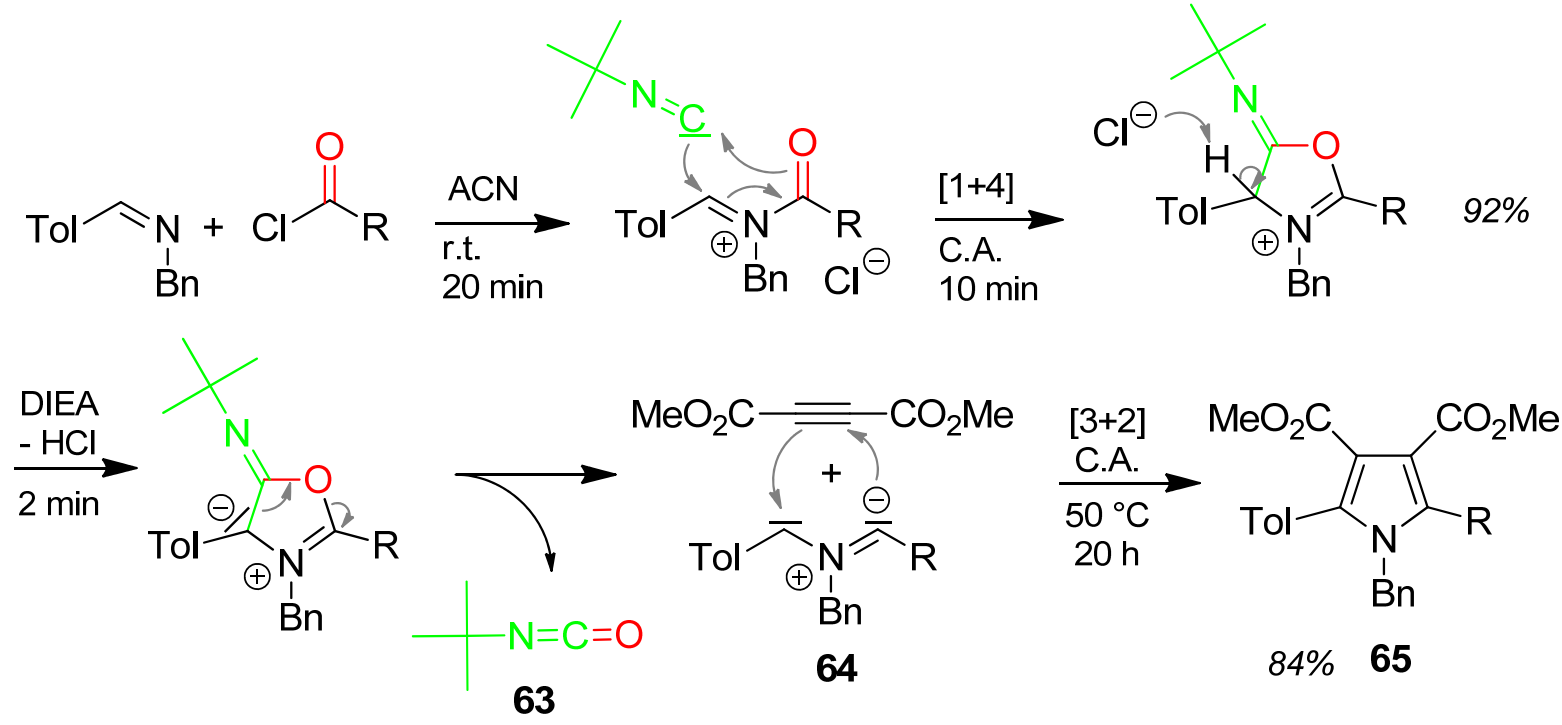

A highly interesting comparison of the same pyrrole synthesis by a 4F3CR catalyzed by $\operatorname{Pd}(0)$, but mediated by $\mathrm{CO}$ instead of isocyanide has been published in the same article [95]. In this case, $\mathrm{CO}_{2}$ is formed by the oxygenation of $\mathrm{CO}$. 


\subsubsection{Ketene 68 Elimination [96]}

Nitrile and acylaminoketone react MW-assisted and fast to form 66. After eliminating the acyl residue the 3,5,6-trisubstituted 2-aminopyridine derivative $\mathbf{6 7}$ is formed in good yields. The side product of the synthesis is the high-energy-molecule ketene $\mathbf{6 8}$, which has been generated in an electrocyclic reaction of $\mathbf{6 3}$ and will further react (Scheme 29) [96].

Scheme 29. Ketene $\mathbf{6 8}$ formation as by-product in a pyridine synthesis.

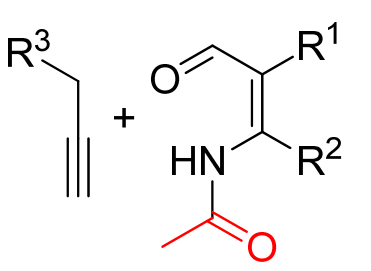

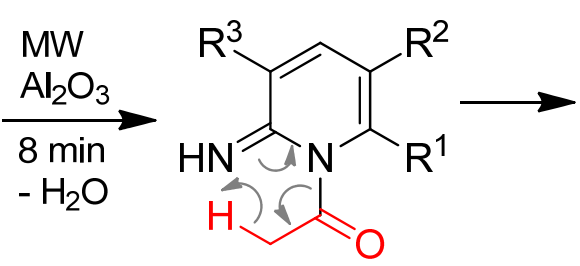

66<smiles>[R]c1cc([R])c(N)nc1[R]</smiles>

$81-88 \%$

\subsection{Isocyanide-Based MCRs (I-MCRs)}

Various types of reactions have been presented and the corresponding reaction mechanisms described for each reaction in Section 2. Most applied functional groups in MCRs are also usual reaction partners in general chemical reactions and some reviews [97-102] have been published on the use of malodinitriles in MCRs [97], 1,3-dicarbonyl building blocks [98,99], aldehydes and $\beta$-ketoesters for Biginelli reactions [100], acetylenedicarboxylates [101], and imine-based MCRs [102].

Isocyanides 69, however, are typical MCR components [6,103-109], and half of the reactions presented in this paper are based on isocyanides. Within the last decade, about a thousand papers on I-MCRs have been published. This outstanding position is the consequence of isocyanides' electronic structure as electron-rich carbenoids (Scheme 30). Whereas mesomer 69 I emphasises the nucleophilic character of the isocyanide, mesomer 69 II demonstrates the carbene nature of the isocyanide with its electron deficient sextet at the $\mathrm{C}$-atom. This makes an isocyanide favored to react with a nucleophile and an electrophile simultaneously in an $\alpha$-addition reaction, the I-3CR (as is P-3CR in sub-section 2.15). Thereby the transition of the divalent carbon $C^{I I}$ of the carbenoid isocyanide into the $\mathrm{sp}^{2}$-hybridised tetravalent $\mathrm{C}^{\mathrm{IV}}$ of the $\alpha$-adduct of the isocyanide with two reaction partners takes place. This is the irreversible step in the reaction of isocyanide-based MCRs and drives the reaction course to the product side.

Scheme 30. Resonance effect of isocyanide 69.

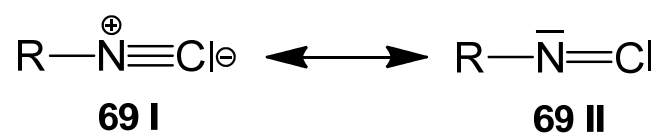

Since the pioneering and seminal research on isocyanide-based MCRs by Passerini and Ugi, who recognized their enormous potential and made this chemistry presentable, many extensions and some new I-MCRs have been created. Outstanding and recently intensively researched reactions are the combination of isocyanides with electron-deficient alkynes as are dialkyl acetylenedicarboxylates, generating the reactive zwitterionic intermediate (as $\mathbf{1 6}$ in sub-section 2.9), which could be trapped by 
a third component $[108,109]$. Several syntheses of this type are presented in sub-sections 2.7 [44], 2.9 [51], 2.20 [84], 2.22 [86], and 2.26 [94] of this paper.

Another important progress is the I-4CR from aldehyde + malodinitrile + imine + isocyanide [97]. Aldehyde and malodinitrile react in a Knoevenagel condensation forming a strong Michael acceptor, which adds as well as the imine to the isocyanide, according to the reaction in sub-section 2.6 [36], and $2.19[79,83]$. A reactive ylide-intermediate makes the reaction definite, achieving high product yields.

\subsection{Isocyanide Generation}

The general and common generation of isocyanides 69 is still the dehydration of the corresponding formamides $\mathbf{7 0}$ by dehydrating reagents such as phosgene (Scheme 31), diphosgene, triphosgene, chloroformates, phosphorous chlorides, sulfonyl chlorides, the Appel reagent (triphenylphosphine/ haloalkanes), CDC (2-chloro-1,3-dimethylimidazolium chloride), and the Burgess reagent (methyl carboxysulfamoyl-triethylammonium ylide) [110]. A solvent-free and safe process to produce phosgene from solid triphosgene in amounts ranging from grams to kilograms is given $[111,112]$.

Scheme 31. Generation of isocyanides from formamides.
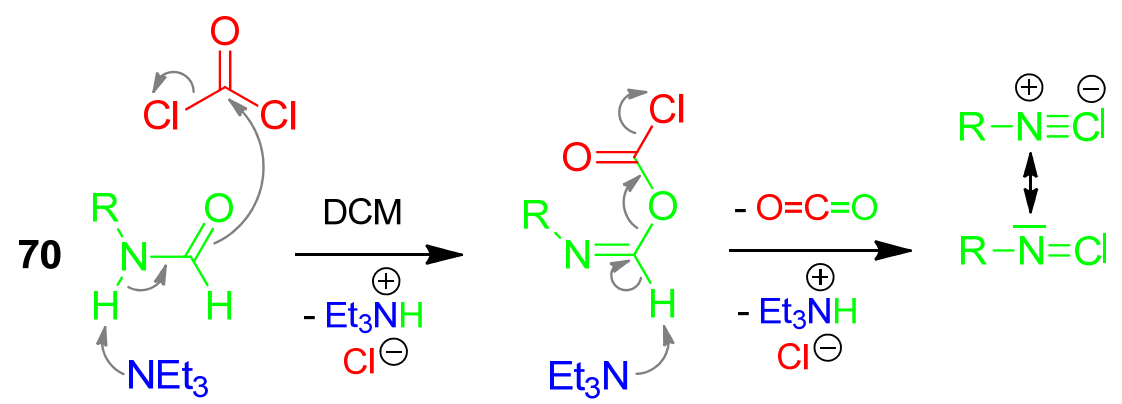

69 I

69 II

A new trend may sometimes help to solve an old problem, namely how to handle the disgusting odour of isocyanides. 1,3-Oxazoles can be easily transformed into isocyanide esters $\mathbf{7 1}$ by ring-opening with $n$-BuLi and acylating the hydroxylic group formed (Scheme 32) [113]. The odours of 71 depend on the acyl group, but are all likable.

Scheme 32. Generation of isocyanides from 1,3-oxazoles.

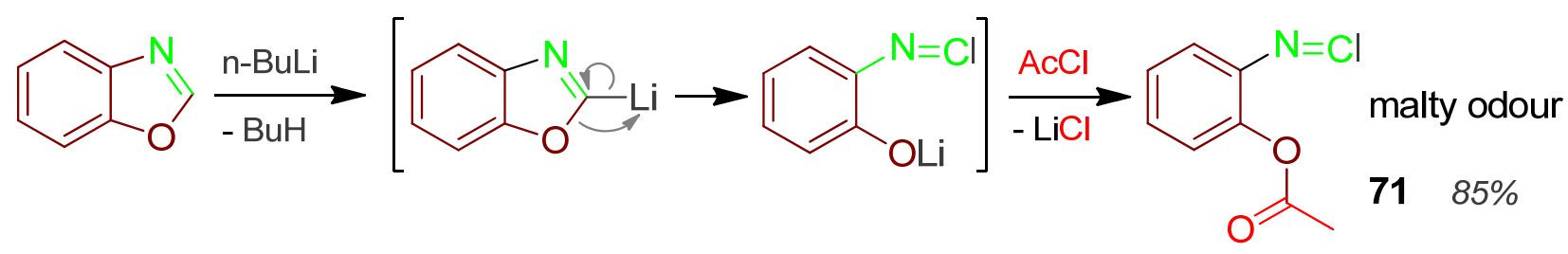

\subsection{Domino Reactions}

Many MCRs are rather tolerant of most other functional groups and these may further react with the newly generated functions of the MCR product in a reaction cascade without additional operations. Thus a high degree of diversity can be achieved. Syntheses in sub-sections 2.14 [64], 2.15 [66], 
2.18 [75], 2.19 [77], and 2.20 [84] contain domino reactions. Finally each MCR itself is a domino reaction. For nomenclature see sub-section 1.2.

\subsection{Post-Condensation-Cyclizations (PCCs)}

The reasons in sub-section 3.4 make MCRs also appropriate for a post-condensation-cyclization (PCC), which can build up a cyclisation reaction using the structure generated by the MCR. The PCC can be a domino reaction. Syntheses in sub-sections 2.10 [53], 2.11 [54], 2.14 [64], 2.15 [66], 2.18 [75], 2.19 [77], 2.20 [84], and 2.25 [93] contain PCCs.

\subsection{Macrocyclization}

The efficient access to macrocyclic structures is still rather difficult. Recent research in this field deals with MCR syntheses of macrocycles, on the approach "multiple multicomponent reaction using two bifunctional building blocks (MiBs)" [114,115].

\section{New Methods in Performing Conditions to Modern Requirements}

Many of the developments of the MCRs in Section 2 are impelled by modern requirements of green chemistry as using water or ionic liquids as solvents or applying solvent-less syntheses and running the reactions at r.t. as well as employing microwave, infrared, or ultrasound irradiation energy in the syntheses.

\subsection{Water as Solvent}

Most MCRs are tolerant of most reaction conditions and non-involved functional groups, so often water, which does not pollute the environment, can be used as solvent, as in sub-sections 2.9 [52], $2.15[68]$, and $2.19[78,80]$. A review on this topic is given [116].

\subsection{Ionic Liquids as Solvent}

The main disadvantage of common solvents is their high vapor pressure, so that losses in the course of a synthesis can be quite substantial and this leakage may pollute the environment. Solvents with a very low vapor pressure could solve the problem. Two kinds of solvents have been proven, ionic liquids (ILs) [117] and long-chained polyethylene glycols. Both have been employed in syntheses of heterocyclic compounds by MCRs. Some syntheses in IL as solvent are described in sub-sections 2.11 [58], and 2.19 [81,82].

\subsection{Solvent-Less Syntheses}

From the ecological and economical points of view, it might be advantageous to run MCRs without any solvent. This will be of course supported by a high ratio of liquid components and their suitable properties. Several syntheses have been carried out with neat components, and detailed studies on this issue have been done in sub-sections 2.4 [33,34], 2.11 [59], 2.17 [74], 2.19 [79], and 2.24 [92]. 


\subsection{Alternative Forms of Energy: Microwave, Infrared, Ultrasound Irradiation}

Conventional thermal heat as a source of the required energy to bring reactions to run is generally and always employable, but this heat is not selective at all. Certain vibrations of bonds in common compounds, however, can be activated selectively and thus less energy input can achieve the same effect as by using conventional heat.

Water, water-containing and similar species with bridged $\mathrm{O}-\mathrm{H}-\mathrm{O}$ or $\mathrm{N}-\mathrm{H}-\mathrm{N}$ bonds can be activated optimally by microwave irradiation (MW). Species containing $\mathrm{C}=\mathrm{O}$ bonds absorb infrared irradiation (IR) very strongly. Reactions wherein generated volatile compounds have to be transferred into the gaseous state by evaporation can be essentially supported by ultrasound.

Several MCRs in this paper have been assisted by energy from MW, as in sub-sections 2.8 [47], 2.11 [58,59], 2.15 [66], 2.19 [78], 2.24 [92], 3.1.2 [96], and in [56].

In the 3CR solvent-less synthesis of 6-aryl-1,2,4,5-tetrazinane-3-thione in sub-section 2.24 reaction times and product yields of both conventional heated and MW assisted reactions have been compared with each other [92]. The efficiency of MW on the reactions has been enormous: reaction times have been reduced to $1 / 15$, whereas the yields doubled concurrently. This should be caused by highly polar reactants. A different effect has been observed in a 4CR synthesizing polyaryl-substituted imidazoles in the ionic liquid butylmethyl imidazolium bromide. Reaction time with heat has been half that of with MW, and yields have been similar in both cases [58]. Here the reactants have been highly non-polar. Reviews on the usage of MW in syntheses of heterocycles by MCRs are given [118-121]. An alternative energy source for reaction activation, even without solvents, is IR [122].

A novel and environmentally-friendly method for preparing dihydropyrano[2,3-c]pyrazoles in water as solvent and under ultrasound irradiation has been developed [52]. Syntheses of pyrazolopyridines have been performed by 3CRs from aldehyde + malodinitrile +3 -aminopyrazole activated with both conventional heat and ultrasound (sub-section 2.19) [83]. Product yields of ten ultrasound activated reactions are on average $60 \%$ higher than those of the same, conventionally heated reactions.

\section{Conclusions}

Figure 1 presents a sketch showing the deeper insight of this review, which demonstrates a nearly unlimited up-growth of novel MCRs forming complex heterocyclic structures. Several new smart strategies in combinations of reacting diverse functional groups have been developed and widened the reaction space of MCRs and thus the scope of their application. Particularly reactions of isocyanides with deactivated alkynes such as acetylenedicarboxylates are widely deployable and eagerly investiga-ted, and other smart MCRs are distinctly coming up. But isocyanide-based MCRs still account for a great part of multi-component reactions.

Also several environmentally-friendly new tools have been employed, referring to the use of solvents and energy source. These may offer economical advantages too. Water is useful as solvent for many syntheses by MCRs, because most of their involved functional groups are neutral against water. In special cases solvent-less syntheses provide great advantages from most points of view. 
Figure 1. Strategies and tools to design DOS for complex heterocycles by MCRs.

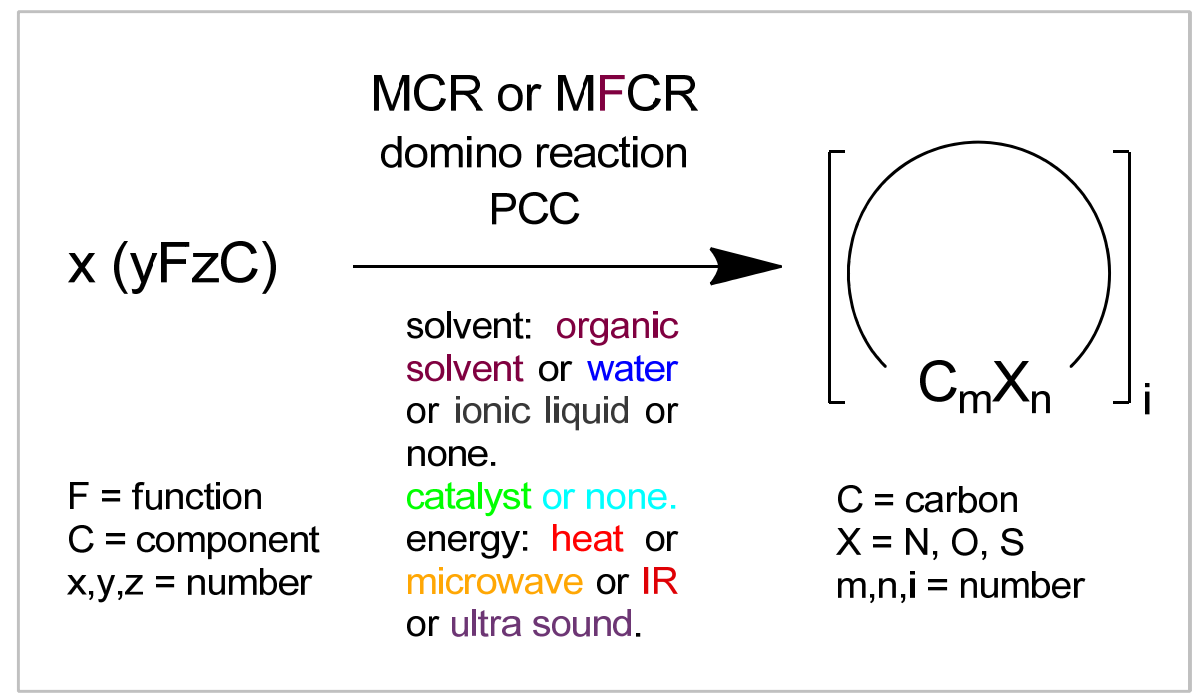

Often the totally unselective conventional heat can be changed by selective microwave irradiation, which may use less energy. Thereby, components may react much faster, achieving very good product yields. This can also be performed in some cases by use of ultrasonic irradiation. Thus, also in the future further substantial and increasing growth in MCRs for performing heterocycle syntheses is to be expected.

\section{References and Notes}

1. Zhu, J., Bienayme, H., Eds. Multicomponent Reactions; Wiley-VCH: Weinheim, Germany, 2005.

2. Eckert, H. From multicomponent-reactions (MCRs) towards multi-function-component-reactions (MFCRs). Heterocycles 2007, 73, 149-158.

3. Katritzky, A.R., Ramsden, C.A., Scriven, E.F.V., Taylor, R.J.K., Eds. Comprehensive Heterocyclic Chemistry III; Elsevier: New York, NY, USA, 2008.

4. Pozharskii, A.F.; Soldatenkov, A.T.; Katritzky, A.R. Heterocycles in Life and Society, 2nd ed.; Wiley \& Sons: New York, NY, USA, 2011.

5. Hemming, K. Heterocyclic chemistry. Annu. Rep. Prog. Chem. B 2011, 107, 118-137.

6. Ugi, I., Ed. Isonitrile Chemistry; Academic Press: New York, NY, USA, 1971.

7. Orru, R.V.A., Ruijter, E., Eds. Synthesis of Heterocycles via Multicomponent Reactions I; Topics in Heterocyclic Chemistry; Springer Verlag: New York, NY, USA, 2010; Volume 23.

8. Orru, R.V.A., Ruijter, E., Eds. Synthesis of Heterocycles via Multicomponent Reactions II; Topics in Heterocyclic Chemistry; Springer Verlag: New York, NY, USA, 2010; Volume 25.

9. Madelung, W. Über eine neue Darstellungsweise für substituierte Indole. Ber. Dtsch. Chem. Ges. 1912, 45, 1128.

10. Houlihan, W.J.; Parrino, V.A.; Uike, Y. Lithiation of $N$-(2-alkylphenyl)-alkanamides and related compounds. A modified Madelung indole synthesis. J. Org. Chem. 1981, 46, 4511-4515.

11. Ito, Y.; Kobayashi, K.; Saegusa, T. An efficient synthesis of indole. J. Am. Chem. Soc. 1977, 99, $3532-3534$. 
12. Burke, M.D.; Schreiber, S.L. A planning strategy for diversity-oriented synthesis. Angew. Chem. Int. Ed. Engl. 2004, 43, 47-58.

13. Sunderhaus, J.D.; Martin, S.F. Applications of multicomponent reactions to the synthesis of diverse heterocyclic scaffolds. Chem. Eur. J. 2009, 15, 1300-1308.

14. Li, M.; Gong, F.-M.; Wen, L.-R.; Li, Z.-R. Expeditious construction of spiro-pyrrolidines by an autocatalytic one-pot, five-component, 1,3-dipolar cycloaddition of in situ generated azo-methine ylides and olefinic dipolarophiles. Eur. J. Org. Chem. 2011, 2011, 3482-3490.

15. Doemling, A.; Herdtweck, E.; Ugi, I. The seven-component reaction. Acta Chem. Scand. 1998, $52,107-113$.

16. Elders, N.; van der Born, D.; Hendrickx, L.J.D.; Timmer, B.J.J.; Krause, A.; Janssen, E.; de Kanter, F.J.J.; Ruijter, E.; Orru, R.V.A. The efficient one-pot reaction of up to eight compo-nents by the union of multicomponent reactions. Angew. Chem. Int. Ed. Engl. 2009, 48, 5856-5859.

17. D'Souza, D.M.; Mueller, T.J.J. Multi-component syntheses of heterocycles by transiton-metal catalysis. Chem. Soc. Rev. 2007, 36, 1095-1108.

18. Weber, L. Multi-component reactions and evolutionary chemistry. Drug Discov. Today 2002, 7, $143-147$.

19. Toure, B.B.; Hall, D.G. Natural product synthesis using multicomponent reaction strategies. Chem. Rev. 2009, 109, 4439-4486.

20. Ganem, B. Strategies for innovation in multicomponent reaction design. Acc. Chem. Res. 2009, 42, 463-472.

21. Syamala, M. Recent progress in three-component reactions. An update. Org. Prep. Proced. Int. 2009, 4, 1-68.

22. Kalinski, C.; Umkehrer, M.; Weber, L.; Kolb, J.; Burdack, C.; Ross, G. On the industrial applications of MCRs: Molecular diversity in drug discovery and generic drug synthesis. Mol. Divers. 2010, 14, 513-522.

23. Biggs-Houck, J.E.; Younai, A.; Shaw, J.T. Recent advances in multicomponent reactions for diversity-oriented synthesis. Curr. Opin. Chem. Biol. 2010, 14, 371-382.

24. Jiang, B.; Rajale, T.; Wever, W.; Tu, S.-J.; Li, G. Multicomponent reactions for the synthesis of heterocycles. Chem. Asian J. 2010, 5, 2318-2335.

25. Ruijter, E.; Scheffelaar, R.; Orru, R.V.A. Multicomponent reaction design in the quest for molecular complexity and diversity. Angew. Chem. Int. Ed. Engl. 2011, 50, 6234-6246.

26. Yu, J.; Shit, F.; Gong, L.-Z. Bronsted-acid-catalyzed asymmetric multicomponent reactions for the facile synthesis of highly enantioenriched structurally diverse nitrogenous heterocycles. Acc. Chem. Res. 2011, 44, 1156-1171.

27. Banfi, L.; Bossio, A.; Guanti, G.; Paravidino, M.; Riva, R. A new highly convergent entry to densely functionalized aziridines based on the Ugi reaction. QSAR Comb. Sci. 2006, 5-6, $457-460$.

28. Concellon, J.M.; Rodriguez-Solla, H. Synthesis and synthetic applications of $\alpha$-amino ketones derived from natural $\alpha$-amino acids. Curr. Org. Chem. 2008, 12, 524-543.

29. Krokotos, C.G.; McGarrigle, E.M.; Aggerwal, V.K.; Varinder, K. Sulfur ylide mediated three-component aziridination and epoxidation reactions using vinyl sulfonium salts. Synlett 2008, 2008, 2191-2195. 
30. Veinberg, G.; Diskovskaya, K.; Vorona, M.; Turkovskis, I.; Kanepe, I.; Lukevics, I. Synthesis of cytotoxic derivatives of 2-oxo-1-acetidinylacetamid. Chem. Heterocycl. Compd. 2005, 41, 93-97.

31. Eckert, H.; Ugi, I. The role of isocyanides in the synthesis of $\beta$-lactam antibiotics and related compounds. In Studies in Natural Products Chemistry; Atta-ur-Rahman, Ed.; Elsevier: New York, NY, USA, 1993; pp. 113-143.

32. Mloston, G.; Celeda, M.; Linden, A.; Heimgartner, H. Two- and three-component reactions leading to new enamines derived from 2,3-dicyanobut-2-enoates. Helv. Chim. Acta 2009, 92, $1520-1537$.

33. Alizadeh, A.; Babaki, M.; Zoreh, N. Solvent-free synthesis of penta-substituted pyrroles: one-pot reaction of amine, alkyl acetoacetate, and fumaryl chloride. Tetrahedron 2009, 65, 1704-1707.

34. Attanasi, O.A.; Favi, G.; Mantellini, F.; Moscatelli, G.; Santeusanio, S. Synthesis of functionalized pyrroles via catalyst- and solvent-free sequential three-component enamine-azoene annulations. J. Org. Chem. 2011, 76, 2860-2866.

35. Kassaee, M.Z.; Masrouri, M.; Partiovi, T. One-pot four-component synthesis of tetra-substituted pyrroles. Helv. Chim. Acta 2008, 91, 227-231.

36. Marandi, G.; Maghsoodlou, M.T.; Hazeri, N.; Habibi-Khorassani, S.M.; Torbati, N.A.; Charati, F.R.; Skelton, B.W.; Makha, M. Synthesis of cyano-2,3-dihydropyrrolo[1,2-f]phenanthridine derivatives via a domino-Knoevenagel-cyclization. Mol. Divers. 2011, 15, 197-201.

37. Crovetto, L.; Rios, R. Three component, highly diastereoselective metal free synthesis of 2,3,4,5 tetrasubstituted pyrrolidines. Synlett 2008, 2008, 1840-1844.

38. Xu, H.-W.; Li, G.-Y.; Wong, M.-K.; Che, C.-M. Asymmetric synthesis of multi-functionalized pyrrolines by a ruthenium porphyrin-catalyzed three-component coupling reaction. Org. Lett. 2005, 7, 5349-5352.

39. Balme, B. Pyrrole syntheses by multicomponent coupling reactions. Angew. Chem. Int. Ed. Engl. 2004, 43, 6238-6241.

40. Smith, N.D.; Huang, D.; Cosford, N.D.P. One-step synthesis of 3-aryl- and 3,4-diaryl-(1H)pyrroles using tosylmethyl isocyanide (TOSMIC). Org. Lett. 2002, 4, 3537-3539.

41. Lin, X.; Mao, Z.; Dai, X.; Lu, P.; Wang, Y. A straightforward one-pot multicomponent synthesis of polysubstituted pyrroles. Chem. Commun. 2011, 47, 6620-6622.

42. Hong, D.; Zhu, Y.; Li, Y.; Lin, X.; Lu, P.; Wang, Y. Three-component synthesis of poly-substituted pyrroles from $\alpha$-diazoketones, nitroalkenes, and amines. Org. Lett. 2011, 13, 4668-4671.

43. Estevez, V.; Villacampa, M.; Menendez, J.J. Multicomponent reactions for the synthesis of pyrroles. Chem. Soc. Rev. 2010, 39, 4402-4421.

44. Alizadeh, A.; Rostamnia, S.; Zhu, L.G. Competition of the R3P/DAAD and RNC/DAAD zwitterions in their production and reaction with aromatic carboxylic acids: A novel binucleo-philic system for three-component synthesis of 2-aminofurans. Synthesis 2008, 2008, 1788-1792.

45. Li, H.; Li, J.; Yan, B.; Li, Y. New domino approach for the synthesis of 2,3-disubstituted benzo[b]furans via copper-catalyzed multi-component coupling reactions followed by cyclization. Tetrahedron Lett. 2009, 50, 2353-2357. 
46. Pan, H.-R.; Li, Y.-J.; Yan, C.-X.; Xing, J.; Cheng, Y. Multicomponent reaction of imidazo[1,5a]pyridine carbenes with aldehydes and dimethyl acetylenedicarboxylate or allenoates: A straightforward approach to fully substituted furans. J. Org. Chem. 2010, 75, 6644-6652.

47. Schirok, H. Microwave-assisted synthesis of $\mathrm{N}$-sec- and $\mathrm{N}$-tert-alkylated indoles. Synthesis 2008, 2008, 1404-1414.

48. Simoneau, C.A.; Ganem, B. Multiple component Fischer indole reactions. Tetrahedron 2005, 61, 11374-11379.

49. Leogane, O.; Lebel, H. One-pot multicomponent synthesis of indoles from 2-iodobenzoic acid. Angew. Chem. Int. Ed. Engl. 2008, 47, 350-352.

50. Kalinski, C.; Umkehrer, M.; Schmidt, J.; Ross, G.; Kolb, J.; Burdack, C.; Hiller, W.; Hoffmann, S.D. A novel one-pot synthesis of highly diverse indole scaffolds by the Ugi/Heck reaction. Tetrahedron Lett. 2006, 47, 4683-4686.

51. Adib, M.; Mohammadi, B.; Bijanzadeh, H.R. A novel one-pot, three-component synthesis of dialkyl 5-(alkylamino)-1-aryl-1H-pyrazole-3,4-dicarboxylates. Synlett 2008, 2008, 3180-3182.

52. Zou, Y.; Wu, H.; Hu, Y.; Liu, H.; Zhao, X.; Ji, H.; Shi, D. A novel and environment-friendly method for preparing dihydropyrano[2,3-c]pyrazoles in water under ultrasound irradiation. Ultrason. Sonochem. 2011, 18, 708-712.

53. Bertozzi, F.; Gundersen, B.V.; Gustavsson, M.; Olson, R. A combinatorial scaffold approach based upon a multicomponent reaction. Org. Lett. 2003, 5, 1551-1554.

54. Sung, K.; Wu, S.H.; Chen, P.I. Facile two-pot syntheses of novel alternating benzene/imidazole systems. Tetrahedron 2002, 58, 5599-5602.

55. Heravi, M.M.; Derikwand, F.; Haghighi, M. Highly efficient, four component, one-pot synthesis of tetrasubstituted imidazoles using a catalytic amount of $\mathrm{FeCl} 3 \times 6 \mathrm{H} 2 \mathrm{O}$. Monatsh. Chem. Chem. Mon. 2008, 139, 31-33.

56. Han, Y.; Xie, Y.-X.; Zhao, L.-B.; Fan, M.-J.; Liang, Y.-M. Synthesis of highly substituted 2imidazolines through a three-component coupling reaction. Synthesis 2008, 2008, 87-93.

57. Sisko, J.; Kanick, A.J.; Mellinger, M.; Filan, J.F.; Allen, A.; Olsen, M.A. An investigation of imidazole and oxazole syntheses using aryl-substituted TosMIC reagents. J. Org. Chem. 2000, $65,1516-1524$.

58. Hasaninejad, A.; Zare, A.; Shekouhy, M.; Rad, J.A. Catalyst-free one-pot four component synthesis of polysubstituted imidazoles in neutral ionic liquid 1-butyl-3-methylimidazolium bromide. J. Comb. Chem. 2010, 12, 844-849.

59. Tavakoli-Hoseini, N.; Davoodnia, A. Carbon-based solid acid as an efficient and reusable catalyst for one-pot synthesis of tetrasubstituted imidazoles under solvent-free conditions. Chinese J. Chem. 2011, 29, 203-206.

60. Masdeu, C.; Gomez, E.; Williams, N.A.O.; Lavilla, R. Double insertion of isocyanides into dihydropyridines: Direct access to substituted benzimidazolium salts. Angew. Chem. Int. Ed. Engl. 2007, 46, 3043-3046.

61. Arevalo, M.J.; Kielland, N.; Masdeu, C.; Miguel, M.; Isambert, N.; Lavilla, R. Multicomponent access to functionalized mesoionic structures based on TFAA activation of isocyanides: Novel domino reactions. Eur. J. Org. Chem. 2009, 617-625. 
62. Yoo, W.-J.; Li, C.-J. Copper-catalyzed four-component coupling between aldehydes, amines, alkynes, and carbon dioxide. Adv. Synth. Catal. 2008, 350, 1503-1506.

63. Lalli, C.; Bouma, M.J.; Bonne, D.; Masson, G.; Zhu, J. Exploiting the divergent reactivity of a-isocyanoacetate: Multicomponent synthesis of 5-alkoxyoxazoles and related heterocycles. Chem. Eur. J. 2011, 17, 880-889.

64. Kolb, J.; Beck, B.; Almstetter, M.; Heck, S.; Herdtweck, E.; Doemling, A. New MCRs: The first 4-component reaction leading to 2,4-disubstituted thiazoles. Mol. Divers. 2003, 6, 297-313.

65. Umkehrer, M.; Kolb, J.; Burdack, C.; Hiller, W. 2,4,5-Trisubstituted thiazole building blocks by a novel multi-component reaction. Synlett 2005, 2005, 79-82.

66. de Moliner, F.; Crosignani, S.; Galatini, A.; Riva, R.; Basso, A. Novel application of $\alpha$-azido aldehydes in multicomponent reactions: Synthesis of triazolo-fused dihydrooxazinones via a passerini reaction-dipolar cycloaddition strategy. ACS Comb. Sci. 2011, 13, 453-457.

67. Akritopoulou-Zanze, I.; Gracias, V.; Djuric, S.W. A versatile synthesis of fused triazolo derivatives by sequential Ugi/alkyne-azide cycloaddition reactions. Tetrahedron Lett. 2004, 45, 8439-8441.

68. Liu, M.; Reiser, O. A copper(I) isonitrile complex as a heterogeneous catalyst for azide-alkyne cycloaddition in water. Org. Lett. 2011, 13, 1102-1105.

69. Whiting, M.; Muldroon, J.; Silverman, S.M.; Lindstrom, W.; Olson, A.J.; Kolb, H.C.; Finn, M.G.; Sharpless, K.B.; Elder, J.H.; Fokin, V.V. Inhibitors of HIV-1 protease by using in situ click chemistry. Angew. Chem. Int. Ed. Engl. 2006, 45, 1435-1439.

70. Lutz, J.F.; Zarafshani, Z. Efficient construction of therapeutics, bioconjugates, biomaterials, and bioactive surfaces using azide-alkyne "click" chemistry. Adv. Drug Deliv. Rev. 2008, 60, 958-970.

71. Gil, M.V.; Arevalo, M.J.; Lopez, O. Click chemistry: What's in a name? Triazol synthesis and beyond. Synthesis 2007, 2007, 1589-1620.

72. Wang, M.-Z.; Xu, H.-W.; Liu, Y.; Wong, M.-K. Stereoselective synthesis of multi-functionalized 1,2,4-triazolidines by a ruthenium porphyrin-catalyzed three-component coupling reaction. Adv. Synth. Catal. 2006, 348, 2391-2396.

73. Castanedo, G.M.; Seng, P.S.; Blaquiere, N.; Trapp, S.; Staben, S.T. Rapid synthesis of 1,3,5-substituted 1,2,4-triazoles from carboxylic acids, amidines, and hydrazines. J. Org. Chem. 2011, 76, 1177-1179.

74. Kundu, D.; Majee, A.; Hajra, A. Indium triflate-catalyzed one-pot synthesis of 1-substituted-1H1,2,3,4-tetrazoles under solvent-free conditions. Tetrahedron Lett. 2009, 50, 2668-2670.

75. Marcos, C.M.; Marcaccini, S.; Menchi, G.; Pepino, R.; Torroba, T. Studies on isocyanides: Synthesis of tetrazolyl-isoindolinones via tandem Ugi four-component condensation / intramolecular amidation. Tetrahedron Lett. 2008, 49, 149-152.

76. Kaim, L.; Grimaud, L.; Patil, P. Three-component strategy toward 5-membered heterocycles from isocyanide dibromides. Org. Lett. 2011, 13, 1261-1263.

77. Bossio, R.; Marcos, C.F.; Marcaccini, S.; Pepino, R. A novel synthetic route to 1,6-dihydro-6oxopyridine-2-carboxylic acid derivatives. Heterocycles 1997, 45, 1589-1592.

78. Tu, S.-J.; Zhang, X.H.; Han, Z.-G.; Cao, X.D.; Wu, S.-S.; Yan, S.; Hao, W.-J.; Zhang, G.; Ma, N. Synthesis of isoxazolo[5,4- $b]$ pyridines by microwave-assisted multi-component reactions in water. J. Comb. Chem. 2009, 11, 428-432. 
79. Kumar, A.; Sharma, S. A grinding-induced catalyst- and solvent-free synthesis of highly functionalized 1,4-dihydropyridines via a domino multicomponent reaction. Green Chem. 2011, 13, 2017-2020.

80. Balamurugan, K.; Perumal, S.; Menendez, J.C. New four-component reactions in water: A convergent approach to the metal-free synthesis of spiro[indoline/acenaphthylene-3,40pyrazolo[3,4-b]pyridine derivatives. Tetrahedron 2011, 67, 3201-3208.

81. Shi, D.-Q.; Yang, F.; Nib, S.N. A facile synthesis of furo[3,4-e]pyrazolo[3,4-b]pyridine-5(7H)one derivatives via three-component reaction in ionic liquid without any catalyst. J. Heterocycl. Chem. 2009, 46, 469-476.

82. Zhang, X.; Li, D.; Fan, X.; Wang, X.; Li, X.; Qu, G.; Wang, J. Ionic liquid-promoted multi-component reaction: novel and efficient preparation of pyrazolo[3,4- $b]$ pyridinone, pyrazolo[3,4-b]-quinolinone and their hybrids with pyrimidine nucleoside. Mol. Divers. 2010, 14, 159-167.

83. Zare, L.; Mahmoodi, O.; Yahyazadeh, A.; Mamaghani, M. Convenient ultrasound-promoted regioselective synthesis of fused 6-amino-3-methyl-4-aryl-1H-pyrazolo[3,4-b]pyridine-5carbonitrile. Synth. Commun. 2011, 41, 2323-2330.

84. Shaabani, A.; Ghadari, R.; Beheshdi, S.; Sarvary, A.; Rezayan, A.H. Synthesis of highly functionalized bis( $4 H$-chromene) and $4 H$-benzo $[g]$ chromene derivatives via an isocyanide-based pseudo-five-component Reaction. J. Org. Chem. 2009, 74, 4372-4374.

85. Ohta, Y.; Oishi, S.; Fujii, N.; Ohno, H. Facile synthesis of 3-(aminomethyl)isoquinolines by copper-catalysed domino four-component coupling and cyclisation. Chem. Comm. 2008, 835-837.

86. Adib, M.; Sayahi, M.-H.; Nosrati, M.; Zhu, L.-G. A novel, one-pot, three-component synthesis of 4H-pyrido[1,2-a]pyrimidines. Tetrahedron Lett. 2007, 48, 4195-4198.

87. Bararjanian, M.; Balalaie, S.; Rominer, F.; Barouti, S. A novel and efficient one-pot synthesis of 2-aminopyrimidinones and their self-assembly. Helv. Chim. Acta 2010, 93, 777-784.

88. Shen, S.; Zhang, H.; Yang, W.; Yu, C.; Yao, C. One-pot combinatorial synthesis of benzo[4,5]imidazo-[1,2-a] thiopyrano[3,4- $d]$ pyrimidin-4(3H)-one derivatives. Chin. J. Chem. 2011, 29, $1727-1731$.

89. AIlyin, A.P.; Trifilenkov, A.S.; Kurashvili, I.D.; Krasavin, M.; Ivachtchenko, A.V. One-step construction of peptidomimetic 5-carbamoyl-4-sulfonyl-2-piperazinones. J. Comb. Chem. 2005, 7, 360-363.

90. Werner, S.; Nielsen, S.D.; Wipf, P.; Turner, D.M.; Chambers, P.G.; Geib, S.J.; Curran, D.P.; Zhang, W. Fluorous parallel synthesis of a piperazinedione-fused tricyclic compoundl library. J. Comb. Chem. 2009, 11, 452-459.

91. Domling, A.; Huang, Y. Piperazine scaffolds via isocyanide-based multicomponent reactions. Synthesis 2010, 2010, 2859-2883.

92. Kanagarajan, V.; Sureshkumar, P.; Thanusu, J.; Gopalakrishnan, M. Environmentally safe one-pot solvent-free synthesis of 6-aryl-1,2,4,5-tetrazinane-3 thiones(ones) catalyzed by NaHSO4-SiO2. Russ. J. Org. Chem. 2009, 45, 1707-1713. 
93. Lezinska, P.; Corres, N.; Moreno, D.; Garcia-Valverde, M.; Marcaccini, S.; Torroba, T. Synthesis of pseudopeptidic (S)-6-amino-5-oxo-1,4-diazepines and (S)-3-benzyl-2-oxo-1,4-benzodiazepines by an Ugi 4CC Staudinger/aza-Wittig sequence. Tetrahedron 2010, 66, 6783-6788.

94. Souldozi, A.; Bouslimani, N.; Welter, R. The reaction of ( $N$-isocyanimino)triphenylphos-phorane with dialkyl acetylenedicarboxylates in the presence of 1,3-diphenyl-1,3-propanedione: A novel three-component reaction for the stereoselective synthesis of dialkyl (Z)-2-(5,7-diphenyl-1,3,4oxadiazepin-2-yl)-2-butenedioates. Tetrahedron Lett. 2007, 48, 2617-2620.

95. Cyr, D.C.; Martin, N.; Arndtsen, B.A. Direct synthesis of pyrroles from Imines, alkynes, and acid chlorides: An isocyanide-mediated reaction. Org. Lett. 2007, 9, 449-452.

96. Sharma, U.; Shahadat, A.; Boruah, R.C. A facile synthesis of annelated pyridines from $\beta$-formyl enamides under microwave irradiation. Tetrahedron Lett. 2000, 41, 3493-3495.

97. Wang, Q.; Song, X.; Yan, C. Application of malononitrile in multicomponent reactions. Huaxue Jinzhan 2009, 21, 997-1007.

98. Bonne, D.; Coquerel, Y.; Constantieux, T.; Rodriguez, J. 1,3-Dicarbonyl compounds in stereoselective domino and multicomponent reactions. Tetrahedron: Asymmetry 2010, 21, 1085-1109.

99. Duque, M.; Allais, C.; Isambert, N.; Constantieux, T.; Rodriguez, J. $\beta$-Diketo building blocks for MCRs-based syntheses of heterocycles. Top. Heterocycl. Chem. 2010, 23, 227-277.

100. Matache, M.; Dobrota, C.; Bogdan, N.D.; Funeriu, D.P. Recent developments in the reactivity of the Biginelli compounds. Curr. Org. Synth. 2011, 8, 356-373.

101. Sun, J.; Wu, Q.; Xia, E.-Y.; Yan, C.G. Molecular diversity of three-component reactions of aromatic aldehydes, arylamines, and acetylenedicarboxylates. Eur. J. Org. Chem. 2011, 2011, 2981-2986.

102. Choudhury, L.H.; Parvin, T. Recent advances in the chemistry of imine-based multicomponent reactions (MCRs). Tetrahedron 2011, 67, 8213-8228.

103. El Kaim, L.; Grimaud, L. Beyond the Ugi reaction: Less conventional interactions between isocyanides and iminium species. Tetrahedron 2009, 65, 2153-2171.

104. Ivachtchenko, A.V.; Ivanenkov, Y.A.; Kysil, V.M.; Krasavin, M.Y.; Ilyin, A.P. Multi-component reactions of isocyanides in the synthesis of heterocycles. Russ. Chem. Rev. 2010, 79, 787-817.

105. Elders, N.; Ruijter, E.; Nenajdenko, V.G.; Orru, R.V.A. $\alpha$-Acidic isocyanides in multicomponent chemistry. Top. Heterocycl. Chem. 2010, 23, 129-159.

106. Sadjadi, S.; Heravi, M.M. Recent application of isocyanides in synthesis of heterocycles. Tetrahedron 2011, 67, 2707-2752.

107. Heravi, M.M.; Moghimi, S. Catalytic multicomponent reactions based on isocyanides. J. Iran. Chem. Soc. 2011, 8, 306-373.

108. de Moliner, F.; Banfi, L.; Riva, R.; Basso, A. Beyond Ugi and Passerini reactions. Multicomponent approaches based on isocyanides and alkynes as an efficient tool for diversity oriented synthesis. Comb. Chem. High Throughput Screen. 2011, 14, 782-810.

109. Shaabani, A.; Maleki, A.; Rezayan, A.H.; Sarvary, A. Recent progress of isocyanide-based multicomponent reactions in Iran. Mol. Divers. 2011, 15, 41-68.

110. Cotarca, L.; Eckert, H. Phosgenations-A Handbook; Wiley-VCH: Weinheim, Germany, 2004; pp. 395-431. 
111. Eckert, H.; Auerweck, J. Solvent-free and safe process for the quantitative production of phosgene from triphosgene by deactivated imino-based catalysts. Org. Process Res. Dev. 2010, 14, 1501-1505.

112. Eckert, H. Phosgenation reactions with phosgene from triphosgene. Chim. OGGI 2011, 29, 40-46.

113. Pirrung, M.C.; Ghorai, S.; Ibarra-Rivera, T.R. Multicomponent reactions of convertible isonitriles. J. Org. Chem. 2009, 74, 4110-4117.

114. Masson, G.; Neuville, L.; Bughin, C.; Fayol, A.; Zhu, J. Multicomponent syntheses of macrocycles. Top. Heterocycl. Chem. 2010, 25, 1-24.

115. Wessjohann, L.A.; Rivera, D.G.; Vercillo, O.E. Multiple multicomponent macrocyclisations (MiBs): A strategic development toward macrocycle diversity. Chem. Rev. 2009, 109, 796-814.

116. Kumaravel, K.; Vasuki, G. Multicomponent reactions in water. Curr. Org. Chem. 2009, 13, $1820-1841$.

117. Isambert, N.; Duque, M.; del Mar, S.; Plaquevent, J.-C.; Genisson, Y.; Rodriguez, J.; Constantieux, T. Multicomponent reactions and ionic liquids: A perfect synergy for eco-compatible heterocyclic synthesis. Chem. Soc. Rev. 2011, 40, 1347-1357.

118. Hugel, H.M. Microwave multicomponent synthesis. Molecules 2009, 14, 4936-4972.

119. Jiang, B.; Shi, F.; Tu, S.-J. Microwave-assisted multicomponent reactions in the heterocyclic chemistry. Curr. Org. Chem. 2010, 14, 357-378.

120. Kruithof, A.; Ruijter, E.; Orru, R.V.A. Microwave-assisted multicomponent synthesis of heterocycles. Curr. Org. Chem. 2011, 15, 204-236.

121. Kadam, A.; Zhang, Z.; Zhang, W. Microwave-assisted fluorous multicomponent reactions. A combinatorial chemistry approach for green organic synthesis. Curr. Org. Synth. 2011, 8, 295-309.

122. Miranda, R.; Noguez, O.; Velasco, B.; Arroyo, G.; Penieres, G.; Martinez, J.O.; Delgado, F. Infrared irradiation: An alternative for reaction activation and its contribution to green chemistry. Educ. Quim. 2009, 20, 421-425.

(C) 2012 by the authors; licensee MDPI, Basel, Switzerland. This article is an open access article distributed under the terms and conditions of the Creative Commons Attribution license (http://creativecommons.org/licenses/by/3.0/). 